\title{
Applicability of Optical and Diffusion Charging-Based Particulate Matter Sensors to Urban Air Quality Measurements
}

\author{
Joel Kuula $^{1^{*}}$, Heino Kuuluvainen ${ }^{2}$, Topi Rönkkö ${ }^{2}$, Jarkko V. Niemi ${ }^{3}$, Erkka Saukko ${ }^{4}$, \\ Harri Portin ${ }^{3}$, Minna Aurela ${ }^{1}$, Sanna Saarikoski ${ }^{1}$, Antti Rostedt ${ }^{2}$, Risto Hillamo ${ }^{1}$, \\ Hilkka Timonen ${ }^{1}$ \\ ${ }^{1}$ Atmospheric Composition Research, Finnish Meteorological Institute, FI-00560 Helsinki, Finland \\ ${ }^{2}$ Aerosol Physics, Faculty of Natural Sciences, Tampere University of Technology, FI-33101 Tampere, Finland \\ ${ }^{3}$ Helsinki Region Environmental Services Authority (HSY), 00240 Helsinki, Finland \\ ${ }^{4}$ Pegasor Oy, 33100 Tampere, Finland
}

\begin{abstract}
High spatial resolution particulate matter measurements are necessary to accurately characterize urban air quality issues. This study investigates how sensors can be used in an urban area to complement existing air quality measurements. A measurement campaign was conducted during winter in Helsinki, Finland, where the performance of a custom-built optical instrument - the Prototype Aerosol Sensor (PAS; uses Shinyei PPD60PV and PPD42NS sensor modules) - and three commercial diffusion charging-based sensors (Pegasor AQ Urban, DiSCmini and Partector) was evaluated against reference instruments. The results showed that the PAS was able to measure the coarse $\left(\mathrm{PM}_{2.5-10} ;\right.$ range: $\left.0-400 \mu \mathrm{g} \mathrm{m}{ }^{-3}\right)$ and fine $\left(\mathrm{PM}_{2.5}\right.$; range: $\left.0-50 \mu \mathrm{g} \mathrm{m}^{-3}\right)$ fractions with reasonably high correlations $\left(\mathrm{R}^{2}=0.87\right.$ and 0.77$)$ when compared to a gravimetric monitor. Likewise, the lung deposited surface area (LDSA) concentrations delivered by the three diffusion charging sensors indicated good performance $\left(\mathrm{R}^{2}: 0.92-0.97\right)$ when compared to LDSA concentrations calculated from the size distribution data of the differential mobility particle sizer. A clear correlation $\left(\mathrm{R}^{2}=0.77\right)$ between the black carbon and Pegasor-measured LDSA concentrations, as well as similar diurnal cycles, was observed, suggesting a common source. The optical sensors were useful for measuring the mass concentrations of coarse local particles. By contrast, the diffusion charging sensors were applicable in urban environments, where ultrafine particles from traffic or other local combustion sources affect air quality.
\end{abstract}

Keywords: Urban air quality; Low-cost sensor; Optical; Diffusion charging; $\mathrm{PM}_{2.5}$.

\section{INTRODUCTION}

Particulate matter (PM) poses health risks to citizens (Brook et al., 2010; Bernard et al., 2001; Bernstein et al., 2008; Chen et al., 2012). It has been estimated that in the EU countries alone a total of 399,000 premature deaths were attributable to fine particle $\left(\mathrm{PM}_{2.5}\right)$ exposure in 2014 (European Environment Agency, 2017). In order to reduce PM exposure, detailed understanding of the spatial and temporal distribution of PM concentrations is required.

The development of high resolution air quality monitoring networks is currently constrained mainly by the high cost of the standardized monitoring instruments (Rai et al., 2017). Additional to high unit cost, unfavorable characteristics

\footnotetext{
* Corresponding author.

Tel.: +358-447227718

E-mail address: joel.kuula@fmi.fi
}

such as large physical size of instruments, limited online data transfer features and excessive complexity of the instrument design and operation create further practical challenges (Moltchanov et al., 2015). As the Ambient Air Quality Directive 2008/EC/50 of EU proposes two different uncertainty levels for standardized $\mathrm{PM}_{2.5}$ and $\mathrm{PM}_{10}$ monitoring equipment $(25 \%$ for continuous and $50 \%$ for indicative), it is worth considering whether less expensive (i.e., indicative) and more convenient instrumentation could be used to complement air quality monitoring (Official Journal of the European Union, 2008).

The proposal of using low-cost sensors as complementing units in existing air quality monitoring networks has been previously discussed in several studies (Rajasegarar et al., 2014; Heimann et al., 2015; Kumar et al., 2015; Castell et al., 2017). Due to the low cost of a sensor, spatial distribution of sparse air quality monitoring networks could be intensified and expanded in a cost-efficient manner. Compact size and low energy consumption would allow independent and wireless operation in locations where convenient measuring 
was previously inconvenient (Devarakonda et al., 2013; Jerrett et al., 2017). Also, sensors could be utilized in mobile and unmanned measurement platforms (Alvarado et al., 2015). Few PM sensor network experiments have been conducted in the past, with fairly positive results (Gao et al., 2015; Jiao et al., 2016). The experiments demonstrated that low-cost sensors may be used to complement existing networks, and furthermore, identify specific pollution hotspots due to the high spatial network resolution.

In order to ensure the appropriateness of sensor measurements, criteria for data quality has to be met. Some studies have indicated that, in some cases, the accuracy of sensors may be questionable when considering parameters for continuous air quality monitoring, e.g., mass concentrations of particulate matter (Zikova et al., 2017). However, several other studies have also indicated that the sensors may be well-suited for complementing existing networks (Wang et al., 2015; Sousan et al., 2017). The inconsistent results indicate that comprehensive understanding of the response characteristics of the sensor is necessary, and that the performance of the sensor has to be validated in the environment in which it will be deployed. Furthermore, different response characteristics emphasizes the need of users to acknowledge the corresponding limitations which the specific sensor may have in certain environments.

The aim of this study was to introduce a field test where the performance of aerosol sensors was evaluated. The evaluated sensors were classified into optical and diffusion charging-based sensors according to their detection method. The optical Prototype Aerosol Sensor (PAS) was a custom built device, which utilized two separate optical sensor modules as its detection units. Commercial Pegasor AQ Urban, Partector and DiSCmini sensors based on diffusion charging and electrical detection of particles were evaluated as well. Conclusions about the performance capabilities and the applicability of each sensor type to an air quality network are presented.

\section{PARTICULATE MATTER SENSORS FOR AIR QUALITY MONITORING}

\section{Optical Low-Cost Sensors}

Optical aerosol sensors usually consist of an infrared (IR) LED or a small power laser placed in an angle (90-135 $)$ against a standard photodiode, which is used to detect the scattered light of illuminated particles. The generated light scattering signal is filtered and amplified, and typically an analogue voltage or pulse width modulation signal is used to represented measured conditions (e.g., pulse count, height or duration). Some sensors have additional light focusing lenses to enhance the light beam intensity. The optic chamber of a sensor is usually constructed of an injection molded plastic body which is placed on top of the electronic circuit board. Metal shielding is added on top of the photodiode to minimize electrical noise.

The simplistic design of sensors presumably leads to the notable low cost. A typical low-cost sensor costs approximately 50 euros which indicates a hundred fold price reduction when compared to a typical medium price range (1,000-15,000 euros) instrument. Along with low cost, the sensors are small and have low power consumption. This makes them an attractive option to be used in monitoring network applications (Kumar et al., 2015).

The disadvantage of low-cost sensors is the unguaranteed accuracy and lack of established scientific literature due to their relative novelty. Some manufacturers provide calibration sheets which, however, tend to be insufficient and do not provide detailed analysis of the sensor response characteristics. Furthermore, the low-cost sensors usually require additional enclosure and data acquisition features for them to be properly used. Interdisciplinary skills are required from scientists when working in the fields of aerosol physics, electronics and programming to develop these sensors into instruments. It is also important to note that depending on the level of hardware upgrades, the sensor may end up being just as expensive as the medium price range products.

The most frequently studied optical sensors appear to be Shinyei PPD42NS (Holstius et al., 2014; Austin et al., 2015; Gao et al., 2015; Wang et al., 2015; Jiao et al., 2016; Kuula et al., 2017; Johnson et al., 2018) and Sharp GP2Y1010AU0F (Alvarado et al., 2015; Wang et al., 2015; Sousan et al., 2016a), although several other similar sensors exist as well. A list of commonly occurring sensors is presented in Table 1. Sensors DSM501A and NIDS SM-PWM-01A-HS appear to be direct replicates of the PPD42NS sensor and similarly, NIDS PSX-01E seems to be a direct replicate of the GP2Y1010AU0F sensor. Furthermore, air quality monitors designed for consumer mass markets, such as AirBeam, Speck, Foobot and Air Quality Egg, utilize sensors listed in Table 1 (Manikonda et al., 2016; Sousan et al., 2017; Zikova et al., 2017).

Low-cost optical sensors have been typically compared to scientific grade reference instruments, such as betaattenuation based BAM-1020 (Met One Instruments Inc., USA) and gravimetric Tapered Element Oscillating Microbalance (TEOM, Thermo Fischer Scientific Inc., USA), and large variation of Pearson correlation coefficients $\mathrm{R}^{2}$ (0.36-0.97) have been observed (Holstius et al., 2014; Gao et al., 2015; Jiao et al., 2016; Sousan et al., 2016b; Kelly et al., 2017). Comparisons to instruments with similar detection techniques (optical), e.g., TSI SidePak and pDR1500 from Thermo Fisher Scientific (Wang et al., 2015; Sousan et al., 2016a), have achieved higher and less variable correlations $\left(\mathrm{R}^{2}: 0.89-0.97\right)$. The studies have also shown that there are variables, such as particle size, that need to be accounted for in evaluations and calibrations and that, for example, the influence of temperature and relative humidity variation in sensor outputs does not seem to be consistent (e.g., Hostius et al., 2014; Gao et al., 2015). Additionally, it is worth pointing out that to interpret the results correctly, it is important to understand the operating principles of different detection techniques at a fundamental level. For example, the PPD42NS sensor has a detection range of $>1 \mu \mathrm{m}$, but it has been used to evaluate ambient $\mathrm{PM}_{2.5}$ values in several studies (Holstius et al., 2014; Gao et al., 2015; Liu et al., 2017), although a significant portion 
Table 1. Summary of commonly appearing optical aerosol sensors and their properties.

\begin{tabular}{|c|c|c|c|c|c|c|}
\hline Sensor model & Manufacturer & $\begin{array}{l}\text { Dimensions } \\
(\mathrm{mm})\end{array}$ & $\begin{array}{l}\text { Weight } \\
\text { (g) }\end{array}$ & $\begin{array}{l}\text { Particle size } \\
(\mu \mathrm{m})\end{array}$ & $\begin{array}{l}\text { Power } \\
(\mathrm{W})\end{array}$ & Price \\
\hline $\mathrm{PPD}^{2} \mathrm{NS}^{a}$ & Shinyei Technology, Japan & $59 \times 49 \times 22$ & 24 & $>1.0$ & 0.45 & $65 €$ \\
\hline PPD20PV & Shinyei Technology, Japan & $88 \times 60 \times 20$ & 36 & $>1.0$ & 0.7 & $\mathrm{n} / \mathrm{a}$ \\
\hline PPD60PV $^{b}$ & Shinyei Technology, Japan & $88 \times 60 \times 20$ & 36 & $>0.5$ & 0.7 & $150 €$ \\
\hline AES-1 & Shinyei Technology, Japan & $90 \times 90 \times 23$ & 120 & $>0.5$ & 3.6 & $450 €$ \\
\hline $\mathrm{GP}_{2 Y 1010 A U 0 F^{c}}$ & Sharp Microelectronics, USA & $46 \times 30 \times 18$ & 16 & $\mathrm{n} / \mathrm{a}$ & 0.1 & $12 €$ \\
\hline 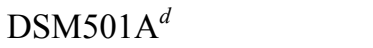 & Samyoung, South Korea & $59 \times 49 \times 22$ & 24 & $>1.0$ & 0.45 & $15 €$ \\
\hline $\mathrm{OPC}-\mathrm{N} 2^{e}$ & Alphasense, UK & $75 \times 53 \times 60$ & 105 & $0.38-17$ & 0.875 & $500 \$$ \\
\hline PMS $1003 / 3003^{f}$ & Beijing Plantower, China & $65 \times 42 \times 23$ & $\mathrm{n} / \mathrm{a}$ & $0.3-10$ & 0.6 & $14 \$$ \\
\hline PMS 5003 & Beijing Plantower, China & $65 \times 42 \times 23$ & $\mathrm{n} / \mathrm{a}$ & $0.3-10$ & 1 & $20 €$ \\
\hline PMS 7003 & Beijing Plantower, China & $48 \times 37 \times 12$ & $\mathrm{n} / \mathrm{a}$ & $0.3-10$ & 0.5 & $45 \$$ \\
\hline NIDS SM-PWM-01A-HS & NIDS, South Korea & $59 \times 46 \times 18$ & 23 & $>1.0$ & 0.5 & $25 \$$ \\
\hline NIDS PSX-01E & NIDS, South Korea & $50 \times 32 \times 27$ & 21 & $>1.0$ & 0.15 & $\mathrm{n} / \mathrm{a}$ \\
\hline SDS011 ${ }^{g}$ & Nova Fitness, China & $71 \times 70 \times 23$ & $\mathrm{n} / \mathrm{a}$ & $0.3-10$ & 1.1 & $36 \$$ \\
\hline
\end{tabular}

${ }^{a}$ Holstius et al., 2014; Austin et al., 2015; Gao et al., 2015; Wang et al., 2015; Jiao et al., 2016; Kuula et al., 2017;

Johnson et al., 2018.

${ }^{b}$ Jiao et al., 2016; Sousan et al., 2017.

${ }^{c}$ Alvarado et al., 2015; Wang et al., 2015; Manikonda et al., 2016; Sousan et al., 2016a; Sousan et al., 2017.

${ }^{d}$ Wang et al., 2015; Manikonda et al., 2016; Sousan et al., 2017; Zikova et al., 2017.

${ }^{e}$ Sousan et al., 2016b.

${ }^{f}$ Kelly et al., 2016.

${ }^{g}$ Liu et al., 2019.

of aerosol mass is in accumulation mode size fraction (0.1-1 $\mu \mathrm{m}$; Hinds, 1999). Despite high variability and challenges in calibration, optical aerosol sensors have been noticed to offer some utility in network and mobile measurement applications.

\section{Diffusion Charging Sensors}

The operation principle of diffusion charging sensors is based on the generation of unipolar ions and mixing them into studied aerosol. This is followed by electrical charging of the particles driven by the diffusional motion of ions to the particles' surfaces. If the charging efficiency of particles is known, the particle concentration can be calculated by collecting the particles and measuring the electric current by a Faraday cup electrometer or, alternatively, without particle collection by measuring the electric charge escaping the charger with the charged particles (Lehtimäki 1983). The particle size dependency of the efficiency of diffusional charging is close to the particle surface area concentration (e.g. Ntziachristos et al., 2007) or, more specifically, lung deposited particle surface area (LDSA) concentration (ICRP, 1994). With additional data, e.g., size distribution of particles, the method can also be used to calculate the particle number or mass concentrations (Rostedt et al., 2014).

Lung deposited surface area is an aerosol related parameter which describes the total surface area of particles (typically $\mathrm{D}_{\mathrm{p}}<100 \mathrm{~nm}$ ) penetrating and depositing to the deepest parts (i.e., alveolar region) of human lungs. High LDSA concentration implies high potential for particle surface related oxidative chemistry and, therefore, this parameter is a subject of interest when considering human health effects of particulate matter. Along with $\mathrm{PM}_{2.5}$ and $\mathrm{PM}_{10}$, particle surface area has been associated with adverse health effects in several toxicological studies (Brown et al., 2001; Oberdörster et al., 2005; Rönkkö et al., 2018). It, however, remains unclear what is the most important health related parameter that should be measured.

Accuracy and comparability of several commercial diffusion charging sensors have been thoroughly investigated (Buonanno et al., 2014; Rostedt et al., 2014; Bau et al., 2015; Todea et al., 2015, 2017). For instance, in the particle size range of $20-400 \mathrm{~nm}$, the LDSA concentrations $\left(\mu \mathrm{m}^{2} \mathrm{~cm}^{-3}\right)$ obtained from the sensors were $\pm 30 \%$ of the LDSA values calculated from the Scanning Mobility Particle Sizer (SMPS) size distribution. And a deviation of $\pm 50 \%$ was observed when the particle number concentration $\left(\# \mathrm{~cm}^{-3}\right.$ ) delivered by the sensors was compared to the particle number concentration measured by an ultrafine condensation particle counter (UCPC; Todea et al., 2017).

Several commercial diffusion charging sensors exist currently and most of them are in the mid-price class. These sensors are, e.g., Partector (Naneo, Switzerland), AQ Urban, AQ Indoor and PPS-M (Pegasor, Finland), Aerasense NanoTracer and Aerasense NanoMonitor (Philips, Netherland), and DiSCmini (Testo, United States). The aforesaid sensors have been used, e.g., in diesel engine exhaust particle studies (Ntziachristos et al., 2004), outdoor air quality studies (Järvinen et al., 2015; Dal Maso et al., 2016), indoor air quality studies (Rivas et al., 2014) and human exposure assessment studies (Niu et al., 2015; Pacitto et al., 2017). For instance, primary measurement signal of the PPS-M sensor has been shown to have linear response to the LDSA concentrations and to the condensation sink of ambient aerosols in urban environments (Järvinen et al., 2015). However, the response to $\mathrm{PM}_{2.5}$ has been noticed to vary depending on the size distribution and hence source 
of the particles. Traffic and airport activities have been observed to be significant source contribution to the LDSA concentrations measured with PPS-M and DiSCmini sensors, respectively (Järvinen et al., 2015; Hudda and Fruin, 2016).

\section{METHODS}

\section{Instruments}

The evaluated sensors in the campaign were custom made PAS and commercial Pegasor AQ Urban, DiSCmini and Partector sensors. All sensors and reference instruments, except Pegasor AQ Urban, were housed inside of a measurement container which had heating and electricity installed. Due to the heating of the container (air-source heat pump) the temperature and relative humidity values remained stable within the container $\left(30.3 \pm 1.3^{\circ} \mathrm{C}\right.$ and $13.1 \pm 3.8 \%$, mean \pm standard deviation measured within the PAS enclosure) and, therefore, the sensitivity of the PAS sensor to these meteorological factors was not investigated. The container dimensions were approximately $5 \times 1.5 \times 2 \mathrm{~m}$. The sample lines of the sensors and of the reference instruments were fed through the container ceiling up into the ambient air. Partector and DiSCmini sensors used a common sample line and an inlet. The sample line was a straight vertical steel pipe of $50 \mathrm{~mm}$ in diameter, and the sensors were attached at the side of this line. A sample drawing fan (flow rate: $170 \mathrm{~L} \mathrm{~min}^{-1}$ ) was placed at the bottom of the $50 \mathrm{~mm}$ line to minimize diffusion losses. The sample line of the PAS sensor was a straight vertical steel pipe of $25 \mathrm{~mm}$ in diameter and a custom made inlet, which prevented rain, insect and coarse matter ingress, was used. The Pegasor AQ Urban, as a self-contained unit with sample heat treatment, was installed outside, on top of the container, as the manufacturer had recommended. No diffusion or inertial deposition losses were accounted for by the sensors. All recorded data of the reference instruments and sensors was averaged to $1 \mathrm{~h}$ resolution.

\section{Prototype Aerosol Sensor}

The PAS used in this experiment has been previously described in detail by Kuula et al. (2017). The PAS uses Shinyei PPD60PV and PPD42NS sensor modules (Shinyei Technology Co., Ltd., Japan) as its detection units. The basic properties of the optical Shinyei sensors declared by the manufacturer are listed in Table 2. The Shinyei sensors were originally chosen to be used due to their differing detection ranges $(>0.5$ and $>1 \mu \mathrm{m})$, low cost and small size. Furthermore, they were available for purchase at a local vendor. The output unit of the Shinyei sensors is Lo Pulse Occupancy (LPO) which is a ratio (from 0 to $100 \%$ ) of the time exceeding threshold voltage to the total measurement time. Two individual LPO pulses are obtained from the Shinyei sensors. In the PAS application the sensor modules were physically connected in series one after each other, and a small rotary vane pump draw the sample through the modules. The sample flow rate was $0.9 \mathrm{~L} \mathrm{~min}^{-}$ 1. An Atmel ATmega328p chip based microcontroller was used to extract the module signals in 5 min sampling intervals, and the data was logged on to an SD card with a timestamp. All hardware components were housed in an IP65-rated (i.e., fully sealed) aluminium alloy enclosure $(200 \times 125 \times 75 \mathrm{~mm}, 940 \mathrm{~g}$, not including other hardware $)$.

Operational detection ranges of the Shinyei PPD42NS and PPD60PV sensors are approximately 1.6-5 $\mu \mathrm{m}$ and $0.55-1.6 \mu \mathrm{m}$, respectively, and particle composition has a minor effect on the Shinyei PPD42NS sensor response (Kuula et al., 2017). The Shinyei sensors correlate better to particle mass concentration than particle number concentration, and due to the bimodal distribution of atmospheric particles, the Shinyei sensors can be used to measure $\mathrm{PM}_{2.5}$ and $\mathrm{PM}_{2.5-10}$ size fractions with indicative accuracy (Kuula et al., 2017). In this paper, the Shinyei PPD60PV signal is considered for correlation with $\mathrm{PM}_{2.5}$ concentration and the PPD42NS with $\mathrm{PM}_{2.5-10}$ concentration.

\section{Commercial Diffusion Charging Sensors}

DiSCmini and Partector are handheld diffusion charging sensors typically used for personal exposure measurements. Basic properties of these sensors are shown in Table 3. Their battery feature enables them to be used also in mobile measurements. Both sensors have a graphical user interface which enables the user to view measurements in real-time. Diagnostics and menu options are also included. Data is stored in an SD memory card. The DiSCmini uses a virtual impactor with a cut-off at $0.7 \mu \mathrm{m}$ as its sampling inlet. The Partector sensor is supplied with a standard $6 \mathrm{~mm}$

Table 2. Properties of the Shinyei PPD42NS and PPD60PV sensor modules declared by the manufacturer.

\begin{tabular}{lll}
\hline Model & PPD42NS & PPD60PV \\
\hline Manufacturer & Shinyei Technology Co., Ltd., Japan & Shinyei Technology Co., Ltd., Japan \\
Dimensions & $59 \times 42 \times 22 \mathrm{~mm}$ & $88 \times 60 \times 22 \mathrm{~mm}$ \\
Weight & $24 \mathrm{~g}$ & $36 \mathrm{~g}$ \\
Power consumption & $0.45 \mathrm{~W}$ & $0.7 \mathrm{~W}$ \\
Supply voltage & $5 \mathrm{VDC}$ & $5 \mathrm{VDC}$ \\
Particle size detection & $>1.0 \mu \mathrm{m}$ & $>0.5 \mu \mathrm{m}$ \\
Wavelength & $940 \mathrm{~nm}$ & $940 \mathrm{~nm}$ \\
Detection type & Forward angle, photometer & Forward angle, photometer \\
Output signal & Pulse width modulation & Pulse width modulation \\
Operating temperature & $0-45^{\circ} \mathrm{C}$ & $0-45^{\circ} \mathrm{C}$ \\
Operating humidity & $<95 \% \mathrm{RH}$ & $<95 \% \mathrm{RH}$ \\
Price & $\sim 70 €$ & $\sim 150 €$ \\
\hline
\end{tabular}


Table 3. Properties of the diffusion charging sensors.

\begin{tabular}{llll}
\hline Model & Pegasor AQ Urban & DiSCmini & Partector \\
\hline Manufacturer & Pegasor Ltd., Finland & Testo Inc., USA & Naneos GmbH., Switzerland \\
Dimensions & $320 \times 250 \times 1000 \mathrm{~mm}$ & $180 \times 90 \times 43 \mathrm{~mm}$ & $134 \times 78 \times 29 \mathrm{~mm}$ \\
Weight & $20 \mathrm{~kg}$ & $0.7 \mathrm{~kg}$ & $0.4 \mathrm{~kg}$ \\
Power consumption & $60 \mathrm{~W}$ & $\mathrm{n} / \mathrm{a}$ & $<1 \mathrm{~W}$ \\
Particle size detection & $>0.01 \mu \mathrm{m}$ & $0.01-0.7 \mu \mathrm{m}$ & $0.01-10 \mu \mathrm{m}$ \\
Sampling frequency & $1 \mathrm{~Hz}$ & $1 \mathrm{~Hz}$ & $0.25 \mathrm{~Hz}$ \\
Sample flow rate & $6 \mathrm{~L} \mathrm{~min}$ & $1 \mathrm{~L} \mathrm{~min}$ & $0.5 \mathrm{~L} \mathrm{~min}$ \\
Weatherproof & Yes & No & No \\
Operating temperature & - & +10 to $+30^{\circ} \mathrm{C}$ & $\mathrm{n} / \mathrm{a}$ \\
Operating humidity & - & $<90 \% \mathrm{RH}$ & $\mathrm{n} / \mathrm{a}$ \\
Battery feature & No & Yes & Yes \\
\hline
\end{tabular}

tube fitting, but the manufacturer recommends that an aftermarket cyclone is used during the measurements. tube fitting, but the manufacturer recommends that an aftermarket cyclone is used during the measurements. Neither of the sensors have a sample treatment system for extreme weather conditions, nor can they be used as yearround, standalone sensors for outdoor measurements without additional enclosure features.

Pegasor AQ Urban is a self-contained air quality measurement instrument with on-board pump, sample drying, and diagnostics. Basic properties of the Pegasor AQ Urban are shown in Table 3. The device operates as an escaping current diffusion charger and it is based on the Pegasor PPS-M sensor. The PPS-M sensor is described in detail in Rostedt et al. (2014) and Järvinen et al. (2014). The sampling for the instrument is from a weather protected, high turnover air inlet enclosure, protected from rainwater, snow, insects and coarse matter ingress. The sample is heated to $+40^{\circ} \mathrm{C}$ to remove water from the particles and prevent fog droplets from entering the sensor. The sensitivity with respect to LDSA is $0.215 \mu \mathrm{m} \mathrm{cm}{ }^{-2} \mathrm{fA}^{-1}$, with sensitivity of the electrometer being in the low fA range at $1 \mathrm{~Hz}$ operation. With longer integration times better sensitivity can be achieved. The nominal integration time is 2 min, but can be adjusted freely.

\section{Reference Instruments}

Two tapered element oscillating microbalance devices (TEOM 1405, Thermo Fisher Scientific Inc., USA) were used as reference instruments to represent mass concentration of $\mathrm{PM}_{2.5}$ and $\mathrm{PM}_{2.5-10}$, and they were set up and operated according to the European Air Quality Directive 2008/50/EC. They used 2.5 and $10 \mu \mathrm{m}$ cut-point inlets and, thereby, the coarse fraction $\left(\mathrm{PM}_{2.5-10}\right)$ mass was calculated by subtracting the $\mathrm{PM}_{2.5}$ concentration from the $\mathrm{PM}_{10}$ concentration. The TEOMs were used to assess the performance of the PAS. Differential Mobility Particle Sizer (DMPS) was used to evaluate the performance of diffusion charging sensors. The DMPS measured particle size distributions from 6 to $800 \mathrm{~nm}$ using an Airmodus CPC A20 and Vienna type DMA. Additionally, Multiangle Absorption Photometer (MAAP; Model 5012, Thermo Fisher Scientific Inc., USA) was used to measure black carbon (BC) when correlation between the $\mathrm{BC}$ and LDSA measured with the Pegasor AQ
Urban sensor was investigated.

\section{Measurement Site}

The measurements were conducted during the winter from November 15, 2016, to February 15, 2017, at Supersite measurement station in Helsinki, Finland. The PAS and Pegasor AQ Urban sensors operated from November 15, 2016, to February 15, 2017, and the DiSCmini and Partector sensors from $16^{\text {th }}$ to $23^{\text {rd }}$ of November and from $18^{\text {th }}$ to $23^{\text {rd }}$ of November 2016, respectively. The Supersite station $\left(60^{\circ} 11^{\prime} \mathrm{N}, 24^{\circ} 57^{\prime} \mathrm{E}, 4 \mathrm{~m}\right.$ above sea level) is located in a busy avenue street canyon with a traffic rate of 28,000 vehicles per workday. The inlets of the Supersite station are less than $1 \mathrm{~m}$ away from the closest street lane (approx. $3 \mathrm{~m}$ above ground level) and, therefore, traffic related aerosols have heavy impact on the measurements. The surrounding buildings along the street were about $17 \mathrm{~m}$ tall (four floors), and the street was oriented in a northwest-southeast direction. The two one-way lanes of the street were separated with a raised median with some trees growing on it. A tram line was also on the median. The Supersite station is one of the fixed measurement sites of the Helsinki metropolitan area. It is operated by the Helsinki Region Environmental Services Authority (HSY).

Particulate matter concentrations are typically much lower in Finland than in other European countries (Sillanpää et al., 2005a, 2006; European Environment Agency, 2017). This is explained, at least partly, by the relatively remote location of the country and by small population. Houses are typically heated with either district heating or by electricity. Significantly elevated particulate matter concentration time periods (episodes) usually result from long-range transported (LRT) $\mathrm{PM}_{2.5}$ pollution originating from eastern and central European countries or from local $\mathrm{PM}_{10}$ street dust (Karppinen et al., 2004; Kupiainen and Tervahattu, 2004; Kupiainen et al., 2005; Sillanpää et al., 2005b; Saarikoski et al., 2007; Niemi et al., 2009). Local fine particulate matter sources in Helsinki area are traffic, wood burning and secondary aerosol formation from biogenic and anthropogenic precursor gases (Saarikoski et al., 2008; Timonen et al., 2008; Saarnio et al., 2010; Carbone et al., 2014; Pirjola et al., 2017). However, wood burning has been shown to have a negligible effect on air quality and on the mass concentration at the Supersite 
station (Helin et al., 2018). High particle number and LDSA concentrations are observed in traffic environments in the Helsinki area (Järvinen et al., 2015; Kuuluvainen et al., 2016; Pirjola et al., 2017).

\section{Statistical Analysis}

In this study coefficient of determination $\left(\mathrm{R}^{2}\right)$, rootmean-square-error (RMSE) and normalized root-meansquare-error (NRMSE) were used to evaluate the tested sensors. The RMSE and NRMSE values were calculated according to Eqs. (1-2), shown below:

$$
\begin{aligned}
& \text { RMSE }=\sqrt{\frac{\sum_{i=1}^{n}\left(x_{i}-y_{i, c a l}\right)^{2}}{n}} \\
& N R M S E=\frac{R M S E}{\bar{x}}
\end{aligned}
$$

where $n$ is the number of sample pairs, $x_{i}$ is the $i^{\text {th }}$ sample of the reference value, $y_{i, c a l}$ is the $i^{\text {th }}$ sample of the calibrated sensor value and $\bar{x}$ is the mean of the reference values. Calibrated sensor values were used to prevent arbitrary unit comparisons (i.e., Lo Pulse Occupancy, $\mu \mathrm{g} \mathrm{\textrm {m } ^ { - 3 }}$ and $\mathrm{pA}, \mu \mathrm{m}^{3} \mathrm{~cm}^{-3}$ ).

In the correlation analysis, piecewise linear regression was used to calculate slope and intercept values which were further used to convert raw data to appropriate unit form (e.g., Lo Pulse Occupancy to $\mu \mathrm{g} \mathrm{m}^{-3}$ ). Linear regression was used because the ability to make slope and intercept comparisons across different studies was considered to be an important feature. In addition to this, the standardized equivalency tests (EU and EPA) of comparing candidate and reference method uses linear regression (European Commission, 2010). Considering this, it appears that, in most cases, it is not justified to introduce more complicated, nonlinear regression techniques to the correlation analysis when investigating the concept of low-cost, less accurate, complementary air quality sensors.

\section{RESULTS AND DISCUSSION}

\section{Prototype Aerosol Sensor $P_{2.5}$ (PPD60PV)}

The PAS measurements lasted for 97 days and a total of 2328 data points ( $1 \mathrm{~h}$ average) were recorded. During this time ambient $\mathrm{PM}_{2.5}$ concentrations measured with the TEOM varied between $0-50 \mu \mathrm{g} \mathrm{m}^{-3}$. Mean concentration level was $8.3 \mu \mathrm{g} \mathrm{m}^{-3}$ and $25^{\text {th }}$ and $75^{\text {th }}$ percentiles were 4.6 and $9.8 \mu \mathrm{g} \mathrm{m}^{-3}$, respectively. Scatter plot and respective time series of PAS and reference instrument TEOM PM $\mathrm{PM}_{2.5}$ are shown in Fig. 1. The scatter plot (a) shows raw PAS $\mathrm{PM}_{2.5}$ data from the full field campaign while the time series (b) shows the calculated PAS $\mathrm{PM}_{2.5}$ concentration data including only the final third of the 3-month long measurement period. The full time series with raw PAS signal is shown in the supplemental material (Fig. S1). The PAS mass concentration values in the time series plot
(Fig. 1(b)) were calculated according to the slope (11) and intercept (1.7) shown in Fig. 1(a) (red solid line fit). Slope and intercept values calculated for the over and under $25^{\text {th }}$ percentile $\left(4.6 \mu \mathrm{g} \mathrm{m}^{-3}\right)$ values are also shown in the figure (dash-dot lines with " $\mathrm{X}$ " and "O" markers).

The relative accuracy during low concentration periods $\left(<4.6 \mu \mathrm{g} \mathrm{m}^{-3}\right)$ appears to be worse than during higher concentration periods $\left(>4.6 \mu \mathrm{g} \mathrm{m}^{-3}\right)$. Calculated RMSE, NRMSE and $\mathrm{R}^{2}$ values were $7.8 \mu \mathrm{g} \mathrm{m}^{-3}, 264 \%$ and 0.02 for the low concentration period and $3.4 \mu \mathrm{g} \mathrm{m}^{-3}, 33.8 \%$ and 0.77 for the higher concentration period. Corresponding slope and intercept (Fig. 1(a); dash-dot lines with "X/O" marks) values were used in these RMSE and NRMSE calculations. For the whole concentration range, the RMSE and NRMSE values were $3.4 \mu \mathrm{g} \mathrm{m}^{-3}$ and $40.9 \%$ and the coefficient of determination was 0.77 .

The better correlation during higher concentration time periods may be explained by the different predominant aerosol type. It is likely that during low concentration times, vehicle exhaust emissions from traffic was the only significant aerosol source and, therefore, the PAS showed a different kind of response. Previous studies show that particles resulting from vehicular exhaust emission are typically $\mathrm{D}_{\mathrm{p}}<100 \mathrm{~nm}$ (e.g., Karjalainen et al., 2016) which cannot be observed reliably with the optical PAS sensor (Kuula et al., 2017). Furthermore, vehicle PM emissions contain black carbon (BC) which, in theory, cannot be observed with detection techniques based on light scattering (Hinds, 1999). The change in the PAS behavior is also shown in the different slope and intercept values calculated for time periods of over and under $4.6 \mu \mathrm{g} \mathrm{m}^{-3}$ level. The calculated slope and intercept values during low concentration times were 51 and -9.2 as opposed to 9.8 and 2.7 when calculated for the medium and higher concentration times. According to this, an onsite-calibration may produce significantly different outcomes depending on the prevailing aerosol type.

Besides exhaust emissions, an aerosol type which would contain mainly particles of $1.6-2.5 \mu \mathrm{m}$ could also explain the poor performance during low concentration time period. Particles larger than $1.6 \mu \mathrm{m}$ size fall outside of the valid detection range of the PAS (PPD60PV, 0.55-1.6 $\mu \mathrm{m}$ ) and, therefore, inaccurate results would be expected. However, this appears to be an implausible explanation as the amount of mass in larger particle size fraction is usually high, not low (Hinds, 1999). The greatest inaccuracies of the PAS $\mathrm{PM}_{2.5}$ were recorded during low mass concentration time periods which suggests that particles smaller than $0.55 \mu \mathrm{m}$ were likely causing the inaccuracies rather than the particles larger than $1.6 \mu \mathrm{m}$. Furthermore, the relevant literature (described in the section "Measurement site") indicates no known mechanism or source which would produce a distribution containing only larger particles $(>1.6 \mu \mathrm{m})$ and not simultaneously smaller ones. The generation processes of small and larger particles are interconnected (i.e., exhaust emissions, street dust resuspension due to vehicles). However, it is worth pointing out that, in spite of the interconnectivity, rainy or otherwise wet conditions may quickly wash-out or completely prevent, e.g., street dust 


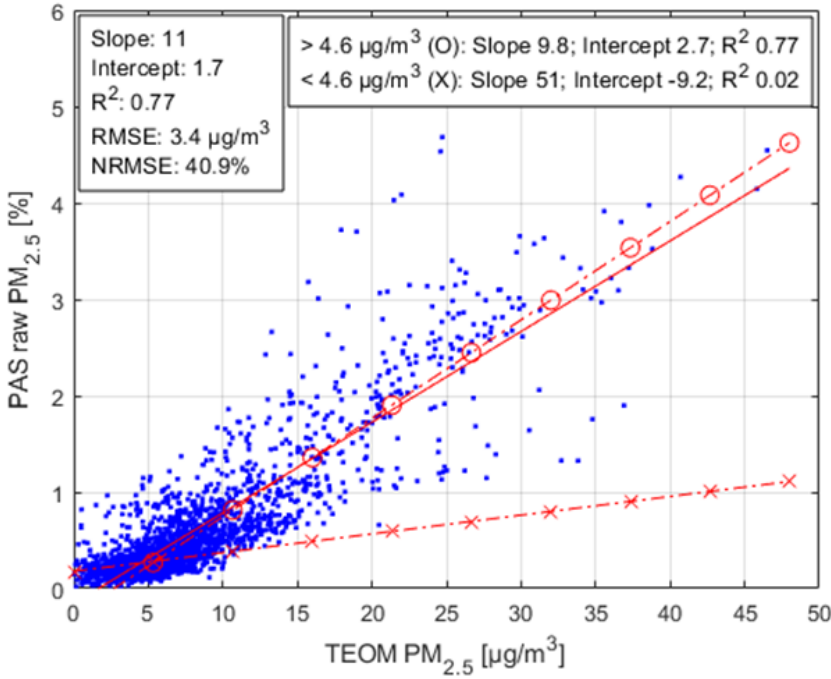

(a)

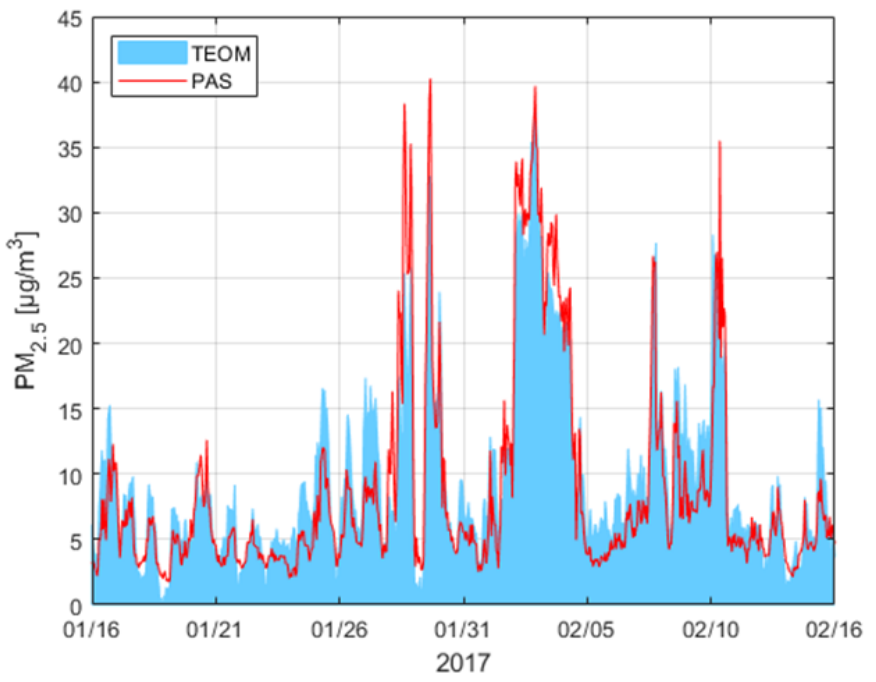

(b)

Fig. 1. (a) TEOM and raw PAS $\mathrm{PM}_{2.5}$ (PPD60PV) scatter plot including all data and (b) time series of the calculated PM 2.5 concentrations including the final third of the measurement campaign. All data is $1 \mathrm{~h}$ averaged.

resuspension. This would lead to conditions where only small (i.e., exhaust emissions) particles are present as inertial-based wash-out processes are much weaker for these particles (Hinds, 1999).

The time series plot (Fig. 1(b)) shows that the PAS was able to detect high $\mathrm{PM}_{2.5}$ concentration episodes (e.g., February 2-5), which resulted most likely from LRT aerosols (Niemi et al., 2004; Timonen et al., 2014). Particles of LRT aerosol have had sufficient time to coagulate and form larger particles, which are therefore close in size to the optimal detection range $(0.55-1.6 \mu \mathrm{m})$ of the PAS (PPD60PV). Gravitational settling and other wash-out processes prevent long-range transportation of large particles (Hinds, 1999).

Diurnal pattern of the $\mathrm{PM}_{2.5}$ measured with the PAS is shown in Fig. 2. The hour of day represents the values calculated from the subsequent hour (e.g., 10 stands for 10:00-11:00). The relatively evenly distributed maximum whiskers (average length and standard deviation of maximum whisker: $31 \pm 4.1 \mathrm{\mu g} \mathrm{m}^{-3}$ ) supports the hypothesis that high concentration aerosols originated elsewhere and not from the local sources (i.e., traffic). High concentration aerosols originating from non-local sources do not show specific diurnal patterns, because the episodes often last several days (Niemi et al., 2004, 2009). For the local sources, the PAS was able to observe traffic related variations (e.g., diurnal variation from $16^{\text {th }}$ to $21^{\text {st }}$ of January, shown in Fig. 1(b)). In this case, traffic related variations refer to particles resulting from other than combustion processes. These particles can be emitted, e.g., from vehicle tires and brakes or from street dust resuspension. Although these particles are mainly over $2.1 \mu \mathrm{m}$ in size, a fraction of the mass (tail end of the distribution) is still found in the lower particle size ranges (Kupiainen et al., 2005). The diurnal pattern measured with the PAS is similar to the one measured with the TEOM $\left(\mathrm{R}^{2}\right.$ correlation of 0.78 between the median hourly values). Diurnal pattern measured with the TEOM is shown in the supplemental material Fig. S2.

Considering the results of the PAS $\mathrm{PM}_{2.5}$, it appears that it cannot be used to measure direct exhaust emission emitted from the vehicles. On the other hand, high concentration episodes caused by the LRT aerosol are observed with the PAS. On-site calibrations have to be conducted carefully with the PAS sensor as different prevailing aerosol types may lead to significantly different outcomes.

\section{$P M_{2.5-10}(P P D 42 N S)$}

During the field campaign $\mathrm{PM}_{2.5-10}$ values measured with the TEOM varied between $0-400 \mu \mathrm{g} \mathrm{m}{ }^{-3}$. Mean concentration was $13.9 \mu \mathrm{g} \mathrm{m}^{-3}$ and $25^{\text {th }}$ and $75^{\text {th }}$ percentiles were 3.4 and $11.3 \mu^{-3} \mathrm{~g} \mathrm{~m}^{-3}$, respectively. The scatter plot (a) and time series (b) of the $\mathrm{PM}_{2.5-10}$ measured with PAS and TEOM are shown in Fig. 3. The scatter plot (a) shows raw PAS $\mathrm{PM}_{2.5-10}$ data from the full field campaign while the time series (b) shows the final third of the 3-month long measurement period. The calculated PAS $\mathrm{PM}_{2.5-10}$ concentration values in the time series plot were calculated according to the slope and intercept shown in Fig. 3(a) (solid red line fit). Slope and intercept values calculated for the time periods when the ratio of TEOM $\mathrm{PM}_{2.5}$ and total mass $\left(\mathrm{PM}_{10}\right)$ was over and under $50 \%\left(\mathrm{PM}_{10}=\mathrm{PM}_{2.5-10}+\mathrm{PM}_{2.5}\right)$ are also shown in the figure (dash-dot lines with " $\mathrm{X}$ " and "O" markers). Reason for this approach is explained further in the manuscript. The full time series with raw PAS $\mathrm{PM}_{2.5-10}$ signal is shown in supplemental material (Fig. S3).

The coarse mode episodes (Fig. 3(b), e.g., on January 25, February 1 and February 8) were caused most likely by the favorable meteorological conditions, which promoted street dust resuspension from drying street surfaces (Kupiainen and Pirjola, 2011; Kupiainen et al., 2016). Particles of coarse mode usually result from abrasion of pavement, winter-sanding materials as well as vehicle tires and brakes. In the Helsinki metropolitan area, studded tires 


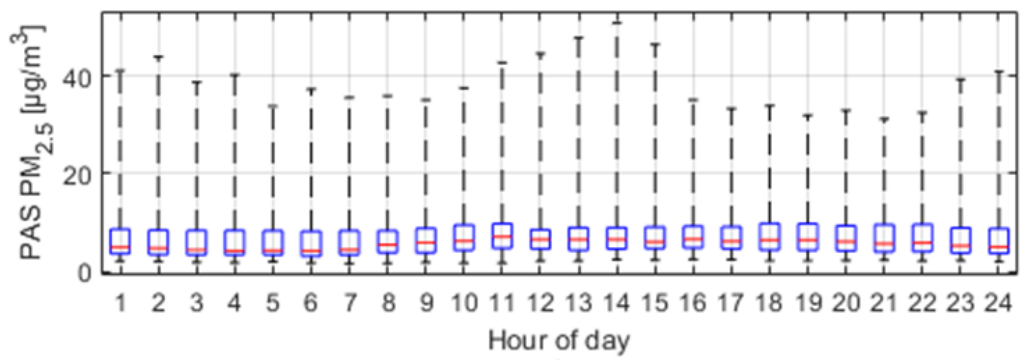

a)

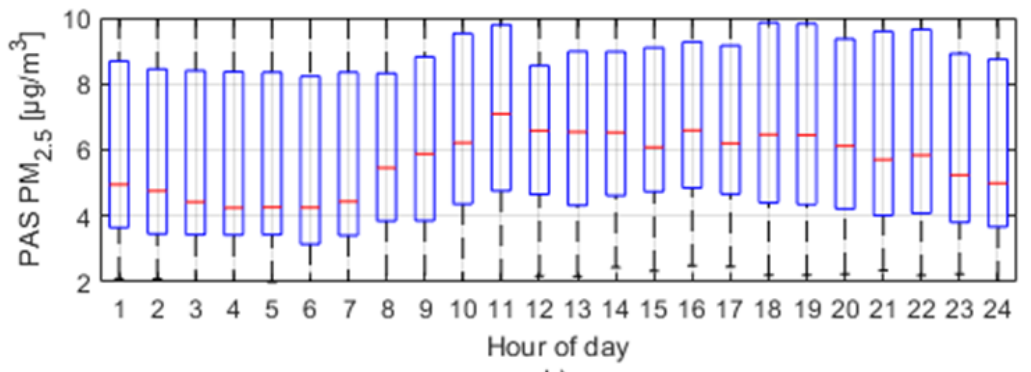

b)

Fig. 2. (a) The average diurnal $\mathrm{PM}_{2.5}$ cycle measured with the PAS sensor. The red lines indicate median; the blue boxes, $25^{\text {th }}$ and $75^{\text {th }}$ percentiles; and the whiskers, the minimum and maximum values. Y-axis is scaled in the (b) panel.

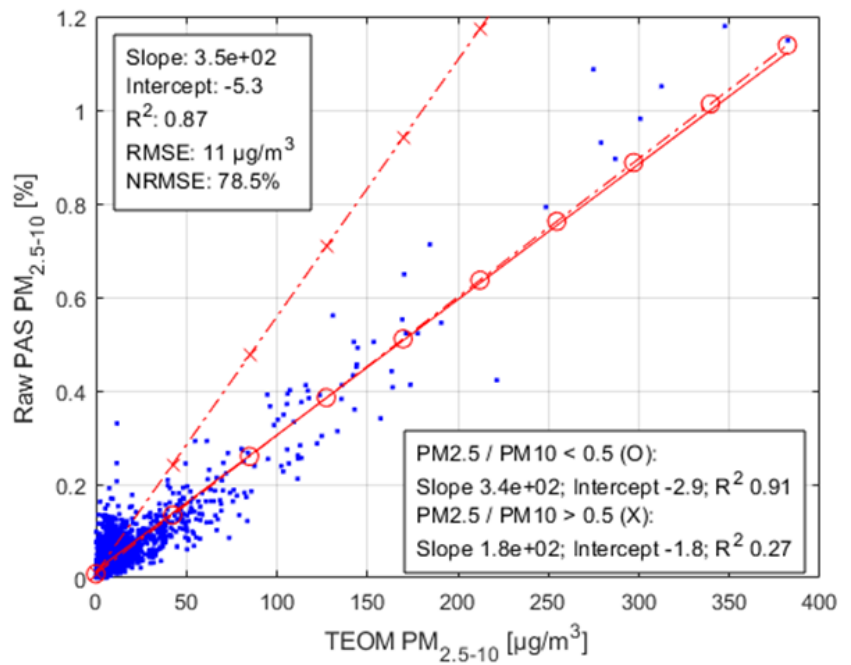

(a)

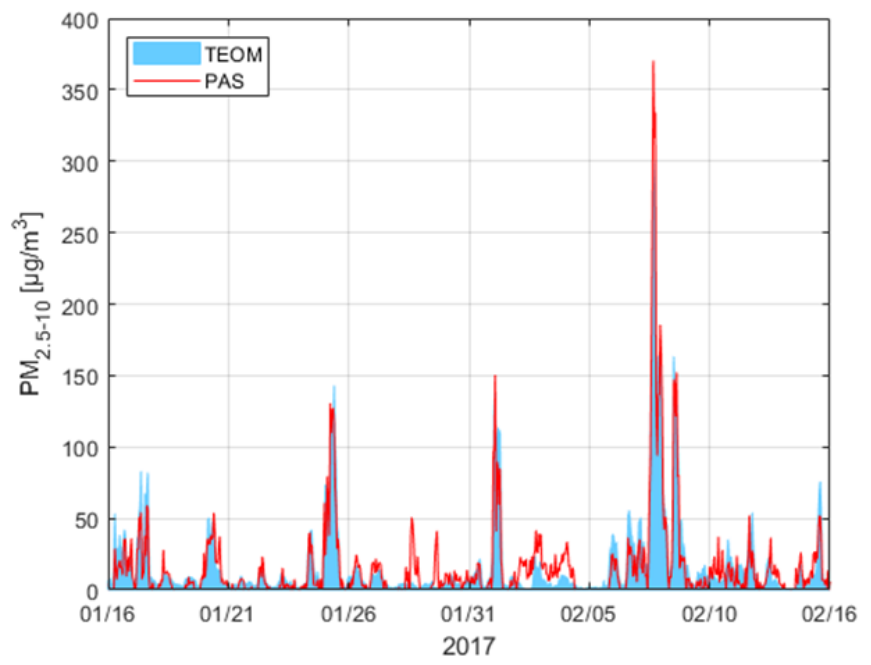

(b)

Fig. 3. (a) TEOM and raw PAS $\mathrm{PM}_{2.5-10}$ (PPD42NS) scatter plot including all data and (b) time series of the calculated $\mathrm{PM}_{2.5-10}$ concentrations including the final third of the measurement campaign. All data is $1 \mathrm{~h}$ averaged.

are commonly used ( $75 \%$ of light duty vehicles) in winter and they intensify the abrasion of pavement. Street dust episodes are common in Finland during winter and spring. The diurnal pattern of the PAS $\mathrm{PM}_{2.5-10}$, shown in Fig. 4, also indicates that the high concentration episodes resulted from local sources as the maximum whiskers are not evenly distributed (short lasting episodes; average length and standard deviation of maximum whisker: $200 \pm 119 \mu \mathrm{g} \mathrm{m}^{-3}$ ). The PAS diurnal cycle is similar to the one measured with the TEOM $\left(\mathrm{R}^{2}=0.84\right)$ which is shown in the supplemental material Fig. S4.

The calculated RMSE, NRMSE and $\mathrm{R}^{2}$ values during high coarse fraction ratio $\left(\mathrm{PM}_{2.5} / \mathrm{PM}_{10}<50 \%\right)$ periods were
$12 \mu \mathrm{g} \mathrm{m}^{-3}, 49.6 \%$ and 0.91 . For low coarse fraction ratio periods $\left(\mathrm{PM}_{2.5} / \mathrm{PM}_{10}>50 \%\right)$ the respective statistics were $4.9 \mu \mathrm{g} \mathrm{m}^{-3}, 111 \%$ and 0.27 . Corresponding slope and intercept (Fig. 3(a); dash-dot lines with "X/O" marks) values were used in these RMSE and NRMSE calculations. For the whole time period the RMSE, NRMSE and $\mathrm{R}^{2}$ values were $11 \mu \mathrm{g} \mathrm{m}^{-3}, 78.5 \%$ and 0.87 . According to the statistics, the PAS $\mathrm{PM}_{2.5-10}$ sensor performs better when the amount of coarse mode particles is comparatively high and vice versa. Following this, the relative fraction of coarse mode particles during high concentration episodes appears to be high as these episodes are detected quite well by the PAS (see Fig. 3(b), e.g., on January 25, February 1 and February 8). 


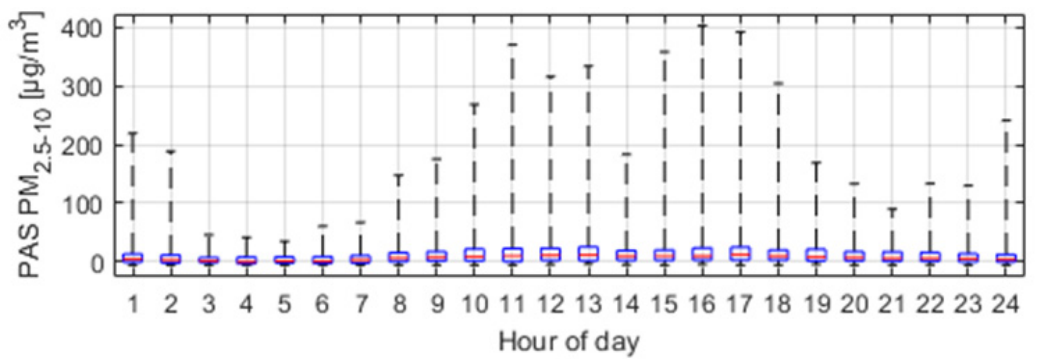

a)

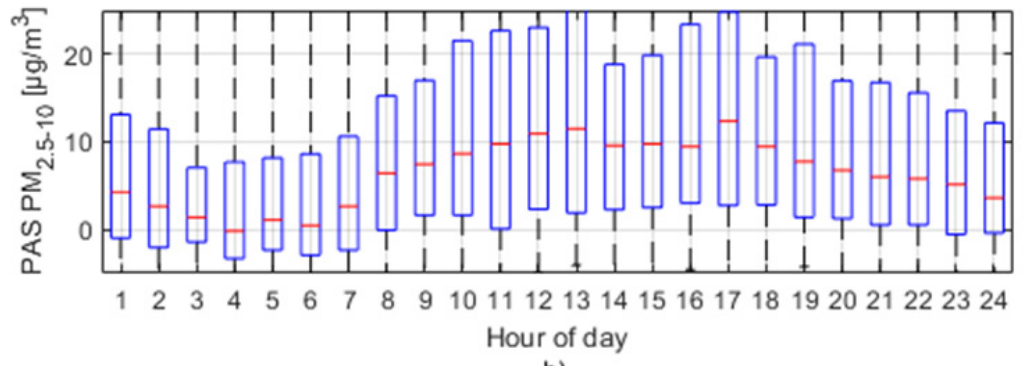

b)

Fig. 4. (a) The average diurnal $\mathrm{PM}_{2.5-10}$ cycle of the PAS. The red lines indicate median; the blue boxes, $25^{\text {th }}$ and $75^{\text {th }}$ percentiles; and the whiskers, the minimum and maximum values. Y-axis is scaled in the (b) panel.

The poor PAS performance during low coarse fraction ratio time periods is most likely explained by the problematic PAS detection range (PPD42NS, 1.6-5 $\mu \mathrm{m}$; Kuula et al., 2017). As approximately $25 \%$ of the valid PAS detection range is accounting for values belonging to $\mathrm{PM}_{2.5}$ fraction, it is expected that during time periods when the fraction of $\mathrm{PM}_{2.5-10}$ is low compared to $\mathrm{PM}_{2.5}$, the PAS accuracy may suffer. This is shown in the statistics described earlier. However, the PAS seems to be well suited for measuring street dust episodes due to their particle size (mainly $>2.1 \mu \mathrm{m}$ ) and relatively high concentration levels. Additionally, the results suggest that it may be possible to increase the PAS $\mathrm{PM}_{2.5-10}$ 's accuracy by investigating the ratios of PPD60PV and PPD42NS signals and, thereby, by using an additional correction factor. This, however, requires additional research.

As Kuula et al. (2017) previously concluded, it appears that the Shinyei sensors measure $\mathrm{PM}_{2.5}$ and $\mathrm{PM}_{2.5-10}$ mass fractions with reasonable accuracy. The inaccuracies are likely caused by the continuously changing size distribution (i.e., varying PM sources, different aerosol type related generation and wash-out processes, and dynamic effects of meteorological factors) as neither of the Shinyei sensors covered the fine and coarse PM size fractions completely. This leads to disproportional weighing of only certain particle sizes. The disproportional weighing might also explain why the results across different studies have varied to a great degree. High correlation results $\left(\mathrm{R}^{2}>0.9\right)$ have been achieved in several laboratory studies (Austin et al., 2015; Wang et al., 2015; Manikonda et al., 2016; Sousan et al., 2017) while simultaneously some field studies have indicated poor $\left(\mathrm{R}^{2}<0.5\right)$ performances (Jiao et al., 2016; Zikova et al., 2017; Johnson et al., 2018). The laboratory conditions might contribute to better recorded performances as the size distributions of produced reference aerosol usually stay more uniform across multiple tests and time.

The influence of temperature and humidity to the PAS performance was not accounted for in this study. Although there were no clear signs of correlation between the PAS performance and meteorological factors measured inside the PAS, a review by Rai et al. (2017) shows that some studies have observed correlations between the Shinyei PPD42NS sensor output and meteorological factors. The PAS was housed inside of a container which had air-source heat pump installed and, therefore, the conditions inside the container remained stable $\left(30.3 \pm 1.3^{\circ} \mathrm{C}\right.$ and $13.1 \pm$ $3.8 \%$ measured inside the PAS sensor enclosure) and the possible influence of meteorological factors was minimized.

\section{Pegasor AQ Urban}

The performance of the Pegasor AQ Urban was evaluated against the results from the DMPS instrument. The LDSA values of the DMPS were calculated according to the alveolar deposition efficiency (ICRP, 1994). For each size bin of the DMPS, the number of measured particles was multiplied by the deposition efficiency of the given particle size. The total surface area of the deposited particles was then calculated accordingly. For the Pegasor AQ Urban, the escaping raw current was used as a representative parameter. Scatter plot of LDSA calculated from the DMPS size distribution data and Pegasor AQ Urban current as well as time series of the LDSA values calculated with these instruments are shown in Fig. 5. The Pegasor AQ Urban LDSA values were calculated according to the slope and intercept shown in Fig. 5(a). The scatter plot represents all of the measurement data and the time series from the final third of the 3-month long measurement period. The full time series with Pegasor AQ Urban raw current is shown in supplemental material (Fig. S3).

The correlation between the DMPS and Pegasor AQ 


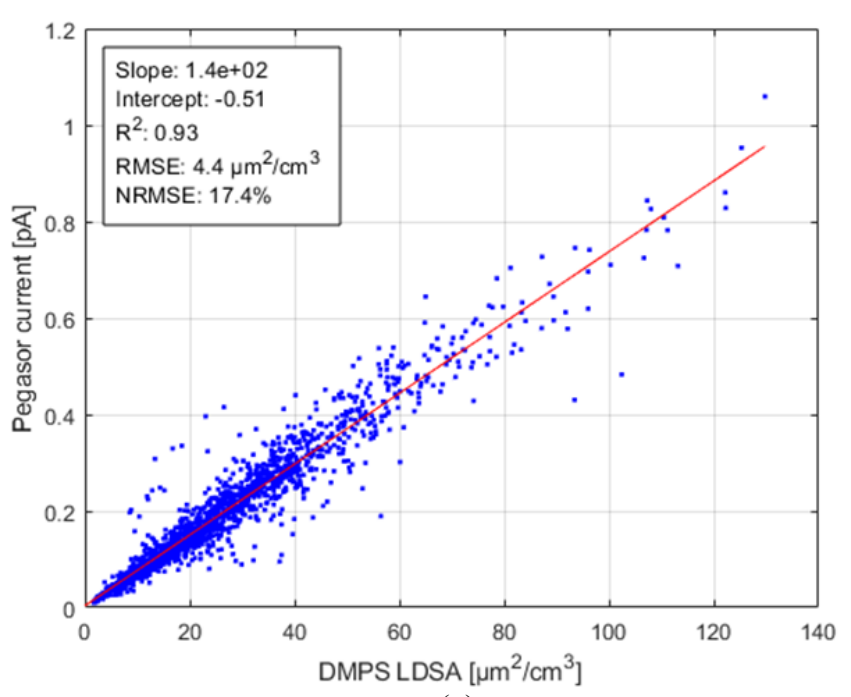

(a)

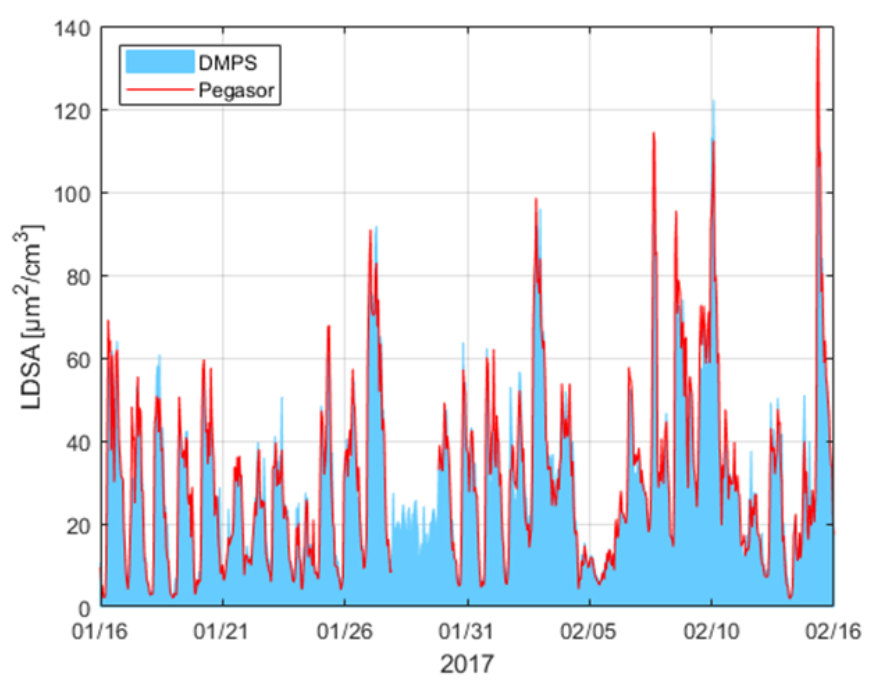

(b)

Fig. 5. (a) Scatter plot and (b) respective time series of the LDSA values calculated from the DMPS and Pegasor AQ Urban raw current. All data is included in the scatter plot but only the last third of the measurements is present in the time series.

Urban was good $\left(\mathrm{R}^{2}=0.93\right)$ during the 3-month long measurement period. Calculated RMSE and NRMSE values were $4.8 \mu \mathrm{m}^{2} \mathrm{~cm}^{-3}$ and $19 \%$. The correlation $\left(\mathrm{R}^{2}=0.77\right)$ between the MAAP BC and the Pegasor AQ Urban current as well as the similar diurnal cycles, as illustrated in Figs. 6 and 7, supports the hypothesis of interconnectivity between LDSA and traffic emissions. The main origin of $\mathrm{BC}$ is incomplete combustion, which in this case is mainly vehicles' exhaust emissions (Viidanoja et al., 2002; Helin et al., 2018). These observations are in line with previous studies conducted in the Helsinki area (Järvinen et al., 2015; Kuuluvainen et al., 2016; Pirjola et al., 2017) and further show that the Pegasor AQ Urban is specifically applicable in urban environments where local traffic emission contribute significantly to the air quality.

\section{DiSCmini and Partector}

The measurement campaigns conducted with the DiSCmini and Partector were shorter than with other evaluated sensors. For the DiSCmini the measurements lasted for 7 days and for the Partector 5 days. The DMPS data converted to the surface area concentrations was used as reference concentration for these instruments. The time series plots and respective scatter plots for both sensors are shown in Figs. 8 and 9, respectively.

The correlations between the sensors and the DMPS were high (DiSCmini: $\mathrm{R}^{2}=0.92$; Partector: $\mathrm{R}^{2}=0.97$ ), and the results are similar to the results of the Pegasor AQ Urban sensor. Calculated RMSE and NRMSE values for the DiSCmini and Partector were $6.5 \mu \mathrm{m}^{2} \mathrm{~cm}^{-3}$ and $21.1 \%$, and $4.3 \mu \mathrm{m}^{2} \mathrm{~cm}^{-3}$ and $14.3 \%$, respectively. Local traffic had an observable effect on the LDSA values, and different pattern during the weekdays (November 16-18 and 21-23, 2016) and weekend (November 19-20) is clearly distinguishable in the time series. In some cases, the double peak resulting from morning and afternoon rush hours can also be seen, for example, on November 21. The average diurnal cycles of the DiSCmini and Partector, shown in Fig. 10, demonstrates the influence of traffic in LDSA measurements.

\section{Comparison of Optical and Diffusion Charging Detection Methods}

The correlation ( $1 \mathrm{~h}$ average) between the calculated $\mathrm{PM}_{2.5}$ concentrations measured with the optical PAS sensor and the calculated LDSA measured with the Pegasor AQ Urban diffusion charging sensor is presented in Fig. 11. The color represents the particle surface area median diameter (SMD) which was calculated from the DMPS data (accounting only for particles smaller than $0.8 \mu \mathrm{m}$ ). A clearly different slope between the instruments for small particles with SMD $<0.18 \mu \mathrm{m}$ and large particle with SMD $>0.18 \mu \mathrm{m}$ was observed. The scatter plot indicates that the optical PAS is suitable for environments where the presence of larger particles, and hence mass, is prevailing. This is true for particles in the accumulation and coarse mode. Therefore, the optical PAS performs optimally when measuring street dust episodes or aged regional/longrange transported aerosols which have had sufficient time to coagulate and condensate and form accumulation mode particles. Previous studies (e.g., Timonen et al., 2008) have shown that in urban background areas the PM mass is typically dominated by accumulation mode particles. The diffusion charging is, on the other hand, especially useful when fresh combustion related anthropogenic particles are the focus of interest. The LDSA values are closely linked to the presence of ultrafine particles $(1-100 \mathrm{~nm})$ due to their very high number concentration and favorable lung deposition efficiency. Therefore, the Pegasor AQ Urban is useful, e.g., in urban areas where the local traffic or other local combustion sources have a significant contribution to the overall air quality. This observation is in line with the results previously published by Rostedt et al. (2014). 


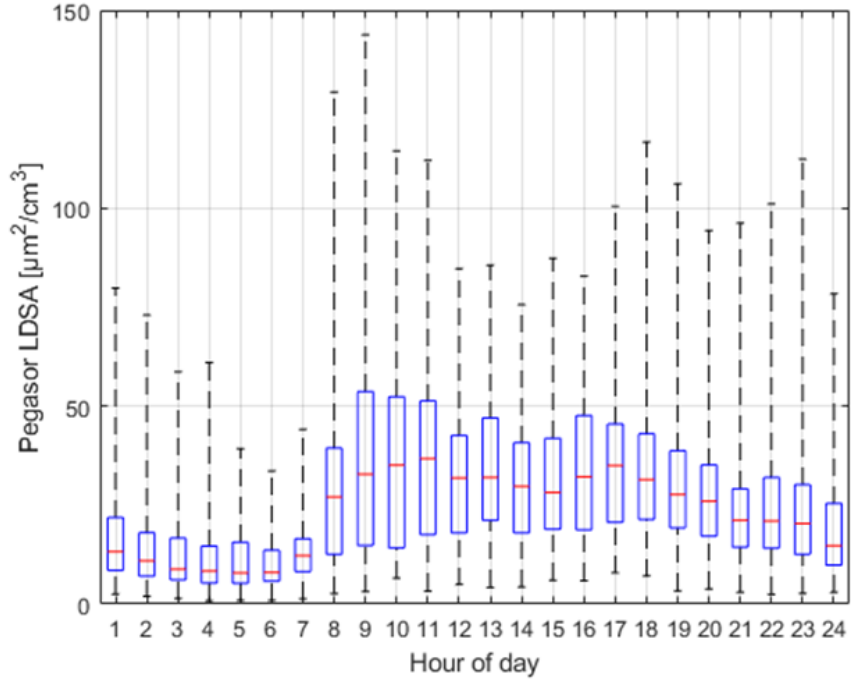

(a)

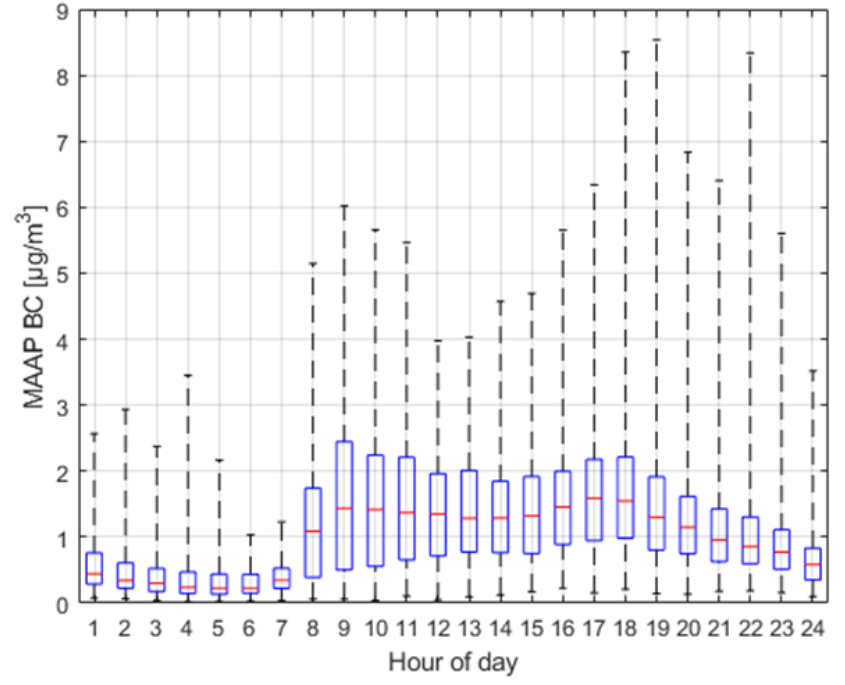

(b)

Fig. 6. The average diurnal cycles measured with the Pegasor AQ Urban (a) LDSA and (b) MAAP BC. The red lines indicate median; the blue boxes, $25^{\text {th }}$ and $75^{\text {th }}$ percentiles; and the whiskers, the minimum and maximum values.

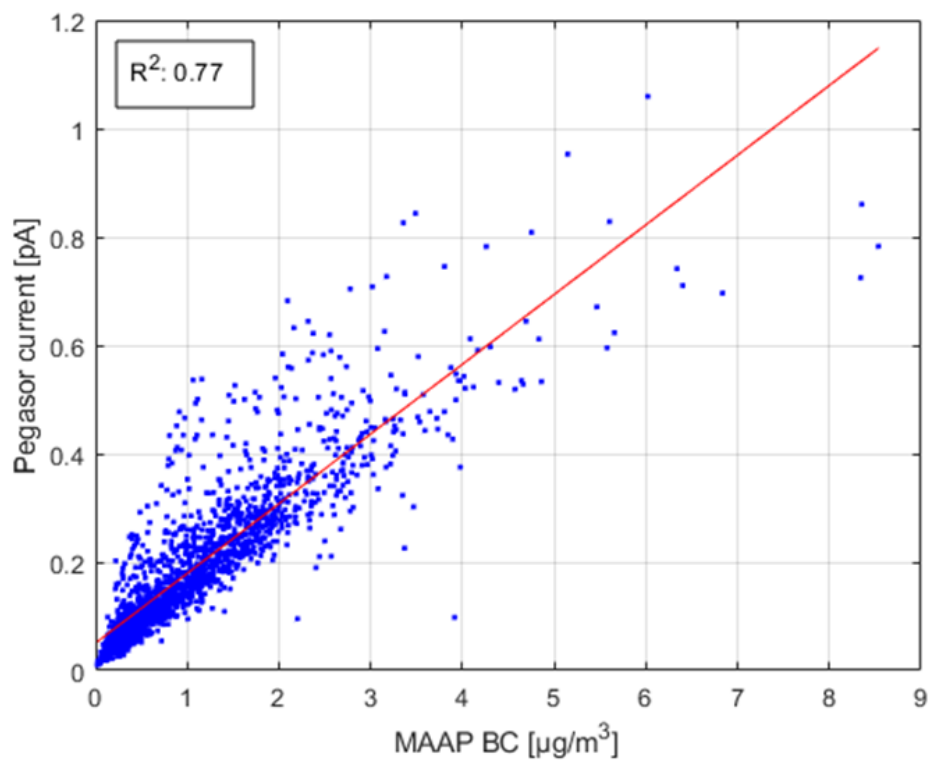

Fig. 7. Scatter plot of the current and BC values measured with the Pegasor AQ Urban and MAAP respectively.

Considering the response differences of the optical and diffusion charging techniques, the required number and density of sensors in a complementary network can be estimated by the expected aerosol types to be measured. For example, in this case the complementary measurements of $\mathrm{PM}_{2.5}$ might not be as useful since most of the episodes are caused by long-range transported aerosols. Therefore, the scarce spatial coverage of the reference-level network is not limiting the measurements. However, highly localized episodes, such as traffic and street dust related episodes, can be identified only at the specific locations in which the reference stations are set. Hence using multiple complementary sensors in targeted locations could bring significant value to the existing monitoring network regarding coarse mode and LDSA detectability.

\section{SUMMARY AND CONCLUSIONS}

A field measurement campaign was conducted to demonstrate the viability of the custom built optical Prototype Aerosol Sensor (PAS) as well as of three commercial diffusion charging sensors (the Pegasor AQ Urban, DiSCmini and Partector) in an urban traffic environment. The correlations between the mass concentrations measured by the reference instrument and those measured by the PAS were fairly good $\left(\mathrm{R}^{2}=0.77\right.$ and 0.87 for $\mathrm{PM}_{2.5}$ and $\mathrm{PM}_{2.5-10}$, respectively), indicating that this low-cost sensor can be useful in complementary monitoring.

The correlations between the lung deposited surface area particle concentrations measured with the three commercial sensors and those calculated from the size distributions 


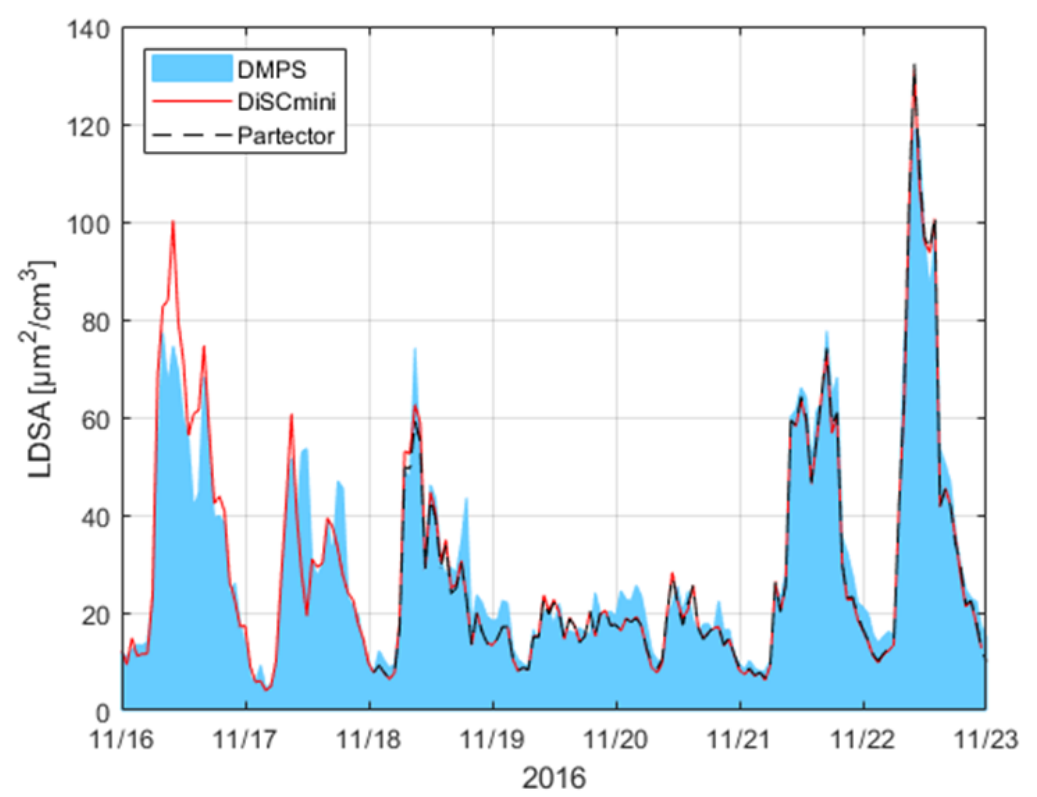

Fig. 8. LDSA time series measured with the DMPS, DiSCmini and Partector.

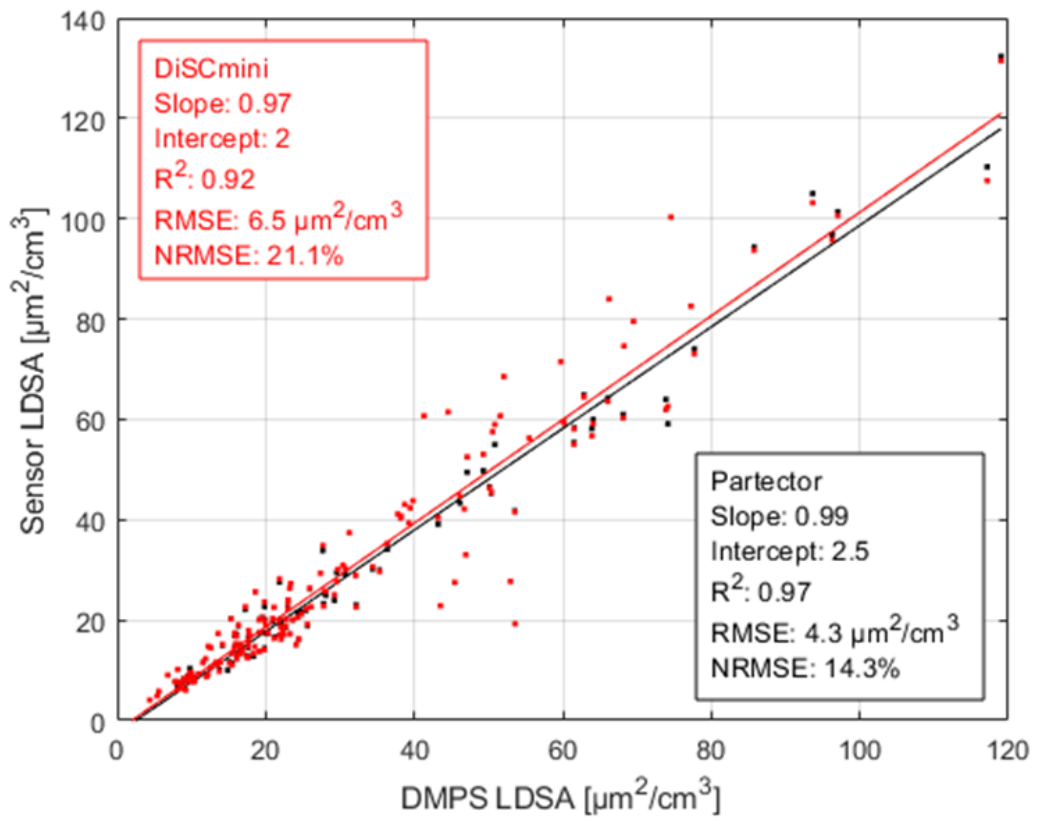

Fig. 9. Correlation plots of the DiSCmini and Partector sensors when compared to DMPS.

measured with the Differential Mobility Particle Sizer were very good $\left(\mathrm{R}^{2}\right.$ : 0.92-0.97). The Pegasor AQ Urban can be reliably used for continuous measurements due to its weatherproofness and long-term stability, whereas the handheld DiSCmini and Partector sensors are better suited to short-term mobile measurements and campaigns due to their battery-powered feature, small size and lack of weatherproofness.

Understanding the different response characteristics across sensor types is required in order to gain the full benefit of sensor measurements. Optical sensors (e.g., the PAS) are suitable for measuring the mass concentrations of aged regional or long-range-transported aerosols containing particles that are larger than approximately $0.5 \mu \mathrm{m}$, and coarse-mode particles. Diffusion-charging-based sensors are best used in locations where traffic exhaust or other local-combustion-related ultrafine particles are the primary source of pollution. An optimized complementary network would utilize both of these sensor types in parallel.

A modern urban air quality network consists of multiple monitoring layers: a reference level using standardized instruments for regulatory monitoring and a complementary sensor type level fulfilling local monitoring needs with regard to a specific aerosol type. Furthermore, research level stations capable of making in-depth analyses of gaseous and aerosol pollutants can be used as a test bed for 


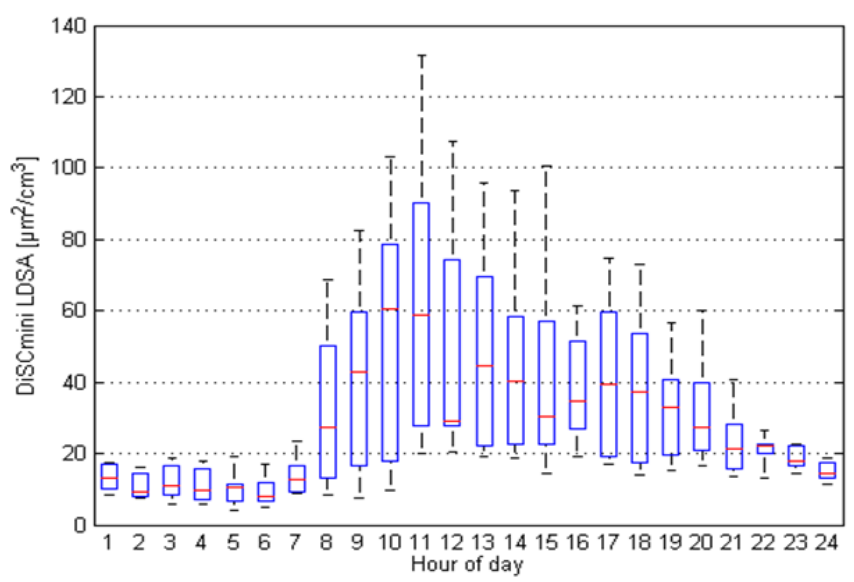

(a)

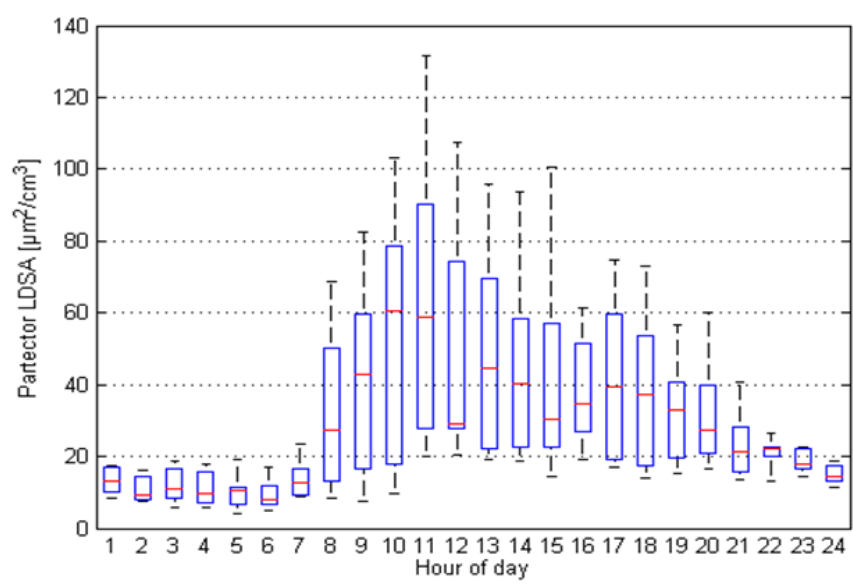

(b)

Fig. 10. Average diurnal LDSA cycles measured with the (a) DiSCmini and (b) Partector. The red lines indicate median; the blue boxes, $25^{\text {th }}$ and $75^{\text {th }}$ percentiles; and the whiskers, the minimum and maximum values.

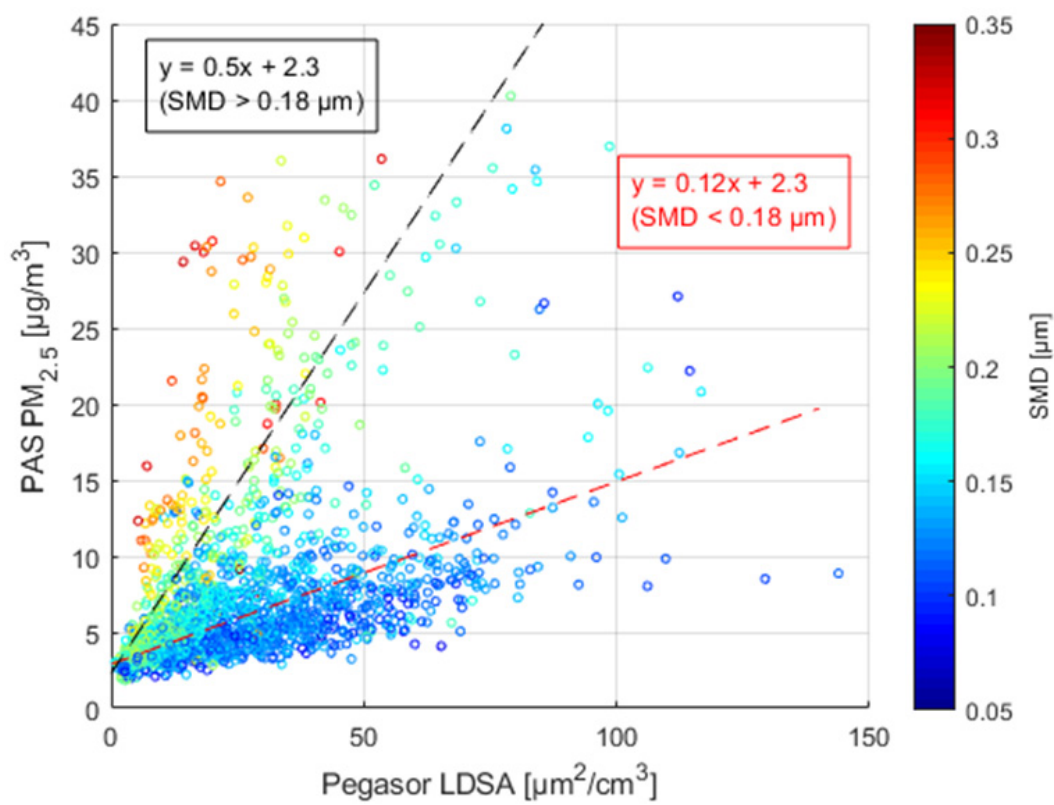

Fig. 11. Scatter plot of the PAS $\mathrm{PM}_{2.5}$ and Pegasor AQ Urban LDSA as a function of particle surface median diameter. The dashed black and red lines represent the corresponding linear fits of data having SMD over (black) and under (red) $0.18 \mu \mathrm{m}$.

less accurate equipment. These stations can also reveal connections between different tracers, such as black carbon, and pollutant parameters, such as LDSA. Along with fixed measurements, mobile measurements (e.g., sensors attached to a public transportation fleet) taken with small battery powered sensors can be used to cost-efficiently expand spatial coverage. A comprehensive and detailed analysis of the spatial distribution of aerosols can be achieved by utilizing the specific strengths of all network layers.

\section{ACKNOWLEDGMENTS}

This study has been funded by TEKES funded INKAILMA/EAKR project (Tekes nro: 4588/31/2015 and 4607/31/2014), CITYZER (Tekes nro: 3021/31/2015 and $2883 / 31 / 2015$ ) and by the regional innovations and experimentations funds AIKO, governed by the HelsinkiUusimaa Regional Council (project HAQT, AIKO014).

\section{COMPETING INTERESTS}

Erkka Saukko works as a senior R\&D engineer at Pegasor Oy. No other author has a competing interest.

\section{SUPPLEMENTARY MATERIAL}

Supplementary data associated with this article can be found in the online version at http://www.aaqr.org.

\section{REFERENCES}

Alvarado, M., Gonzalez, F., Fletcher, A. and Doshi, A. 
(2015). Towards the development of a low cost airborne sensing system to monitor dust particles after blasting at open-pit mine sites. Sensors 15: 19703-19723.

Austin, E., Novosselov, I., Seto, E. and Yost, M.G. (2015). Laboratory evaluation of the Shinyei PPD42NS lowcost particulate matter sensor. PLoS One 10: e0137789.

Bau, S., Zimmermann, B., Payet, R. and Witschger, O. (2015). A laboratory study of the performance of the handheld diffusion size classifier (DiSCmini) for various aerosols in the 15-400 nm range. Environ. Sci. Processes Impacts 17: 261-269.

Bernard, S.M., Sarmet, J.M., Grambsch, A., Ebi, K.L. and Romieu, I. (2001). The potential impacts of climate variability and change on air pollution-related health effects in the United States. Environ. Health Perspect. 109: 199-209.

Bernstein, J.A., Alexis, K., Bacchus, H., Bernstein, L.I., Fritz, P., Horner, E., Li, N., Mason, S., Nel, A., Oulette, J., Reijula, K., Reponen, T., Seltzer, J., Smith, A. and Tarlo, S.T. (2008). The health effects of nonindustrial indoor air pollution. J. Allergy Clin. Immunol. 121: 585591.

Brook, R.D., Rajagopalan, S., Pope, C.A., Brook, J.R., Bhatnagar, A., Diez-Roux, A., Holguin, F., Hong, Y., Luepker, R.V., Mittleman, M.A., Peters, A., Siscovick, D., Smith, S.C., Whitsel, L. and Kaufman, J.D. (2010). Particulate matter air pollution and cardiovascular disease. Circulation 121: 2331.

Brown, D.M., Wilson, M.R., MacNee, W., Stone, V. and Donaldson, K. (2001). Size-dependent proinflammatory effects of ultrafine polystyrene particles: A role for surface area and oxidative stress in the enhanced activity of ultrafines. Toxicol. Appl. Pharmacol. 175: 191-199.

Buonanno, G., Jayaratne, R.E., Morawska, L. and Stabile, L. (2014). Metrological performances of a diffusion charger particle counter for personal monitoring. Aerosol Air Qual. Res. 14: 156-167.

Carbone, S., Aurela, M., Saarnio, K., Saarikoski, S., Timonen, H., Frey, A., Sueper, D., Ulbrich, I.M., Jimenez, J.L., Kulmala, M., Worsnop, D.R. and Hillamo, R. (2014). Wintertime aerosol chemistry in sub-arctic urban air. Aerosol Sci. Technol. 48: 313-323.

Castell, N., Dauge, F.R., Schneider, P., Vogt, M., Lerner, U., Fishbain, B., Broday, D. and Bartonova, A., (2017). Can commercial low-cost sensor platforms contribute to air quality monitoring and exposure estimates? Environ. Int. 99: 293-302.

Chen, R., Kan, H., Chen, B., Huang, W., Bai, Z., Song, G. and Pan, G. (2012). Association of particulate air pollution with daily mortality: The China air pollution and health effects study. Am. J. Epidemiol. 175: 11731181.

Dal Maso, M., Gao, J., Järvinen, A., Li, H., Luo, D., Janka, K. and Rönkkö, T. (2016). Improving urban air quality measurements by a diffusion charger based electrical particle sensors - A field study in Beijing, China. Aerosol Air Qual. Res. 16: 3001-3011.

Devarakonda, S., Sevusu, P., Liu, H., Liu, R., Iftode, L. and Nath, B., (2013). Real-time air quality monitoring through mobile sensing in metropolitan areas. Proceedings of the $2^{\text {nd }}$ ACM SIGKDD International workshop on urban computing, UrbComp 2013 - Held in Conjunction with KDD 2013, Article No. 15.

European Commission (2010). Guide to the demonstration of equivalence of ambient air monitoring methods. $\mathrm{http} / / /$ ec.europa.eu/environment/air/quality/legislation/p df/equivalence.pdf

European Environment Agency (2017). Air quality in Europe - 2017. Report No. 13. Doi: 10.2800/358908.

Gao, M., Cao, J., and Seto, E. (2015). A distributed network of low-cost continuous reading sensors to measure spatiotemporal variations of $\mathrm{PM}_{2.5}$ in Xi'an, China. Environ. Pollut. 199: 56-65.

Heimann, I., Bright, V.B., McLeod, M.W., Mead, M.I., Popoola, O.A.M., Stewart, G.B. and Jones, R.L., (2015). Source attribution of air pollution by spatial scale separation using high spatial density networks of lowcost air quality sensors. Atmos. Environ. 113: 10-19.

Helin, A., Niemi, J.V., Virkkula, A., Pirjola, L., Teinilä, K., Backman, J., Aurela, M., Saarikoski, S., Rönkkö, T., Asmi, E. and Timonen, H. (2018). Characteristics and source apportionment of black carbon in the Helsinki metropolitan area, Finland. Atmos. Environ. 190: 87-98.

Hinds, W.C. (1999). Aerosol technology: Properties, behaviour, and measurement of airborne particles. $2^{\text {nd }}$ Edition, Wiley, Hoboken, NJ, USA.

Holstius, D.M., Pillarisetti, A., Smith, K.R. and Seto, E. (2014). Field calibrations of a low-cost aerosol sensor at a regulatory monitoring site in California. Atmos. Meas. Tech. 7: 1121-1131.

Hudda, N. and Fruin, S.A. (2016). International airport impacts to air quality: Size and related properties of large increases in ultrafine particle number concentrations. Environ. Sci. Technol. 50: 3362-3370.

ICRP (1994). Human respiratory tract model for radiological protection. A report of a task group of the international comission on radiological protection. ICRP Publication 66, Pergamon Press, Oxford, UK.

Järvinen, A., Kuuluvainen, H., Niemi, J.V., Saari, S., Dal Maso, M., Pirjola, L., Hillamo, R., Janka, K., Keskinen, J. and Rönkkö, T. (2015). Monitoring urban air quality with a diffusion charger based electrical particle sensor. Urban Clim. 14: 441-456.

Jerrett, M., Donaire-Gonzalez, D., Popoola, O., Jones, R., Cohen, R.C., Almanza, E., de Nazelle, A., Mead, I., Carrasco-Turigas, G., Cole-Hunter, T., Triguero-Mas, M., Seto, E. and Nieuwenhuijsen, M. (2017). Validating novel air pollution sensors to improve exposure estimates for epidemiological analyses and citizen science. Environ. Res. 158: 286-294.

Jiao, W., Hagler, G., Williams, R., Sharpe, R., Brown, R., Garver, D., Judge, R., Caudill, M., Rickard, J., Davis, M., Weinstock, L., Zimmer-Dauphinee, S. and Buckley, K. (2016). Community air sensor network (CAIRSENSE) project: Evaluation of low-cost sensor performance in a suburban environment in the southeastern United States. Atmos. Meas. Tech. 9: 5281-5292.

Johnson, K.K., Bergin, M.H., Russell, A.G. and Hagler, 
S.W. (2018). Field test of several low-cost particulate matter sensors in high and low concentration urban environments. Aerosol Air Qual. Res. 18: 565-578.

Karjalainen, P., Timonen, H., Saukko, E., Kuuluvainen, H., Saarikoski, S., Aakko-Saksa, P., Murtonen, T., Bloss, M., Dal Maso, M., Simonen, P., Ahlberg, E., Svenningsson, B., Brune, W.H., Hillamo, R., Keskinen, J. and Rönkkö, T. (2016). Time-resolved characterization of primary particle emissions and secondary particle formation from a modern gasoline passenger car. Atmos. Chem. Phys. 16: 8559-8570.

Karppinen, A., Härkönen, J., Kukkonen, J., Aarnio, P. and Koskentalo, T. (2004). Statistical model for assessing the portion of fine particulate matter transported regionally and long range to urban air. Scand. J. Work Environ. Health 30: 47-53.

Kelly, K.E., Whitaker, J., Petty, A., Widmer, C., Dybwad, A., Sleeth, D., Martin, R. and Butterfield, A. (2017). Ambient and laboratory evaluation of a low-cost particulate matter sensor. Environ. Pollut. 221: 491500 .

Kumar, P., Morawska, L., Martani, C., Biskos, G., Neophytou, M., Di Sabatino, S., Bell, M., Norford, L. and Britter, R. (2015). The rise of low-cost sensing for managing air pollution in cities. Environ. Int. 75: 199205.

Kupiainen, K. and Pirjola, L., (2011). Vehicle non-exhaust emissions from the tyre-road interface-effect of stud properties, traction sanding and resuspension. Atmos. Environ. 45: 4141-4146.

Kupiainen, K. and Tervahattu, H. (2004). The effect of traction sanding on urban suspended particles in Finland. Environ. Monit. Assess. 93: 287-300.

Kupiainen, K., Ritola, R., Stojiljkovic, A., Pirjola, L., Malinen, A. and Niemi, J. (2016). Contribution of mineral dust sources to street side ambient and suspension $\mathrm{PM}_{10}$ samples. Atmos. Environ. 147: 178-189.

Kupiainen, K., Tervahattu, H., Räisänen, M., Mäkelä, T., Aurela, M. and Hillamo, R. (2005). Size and composition of airborne particles from pavement wear, tires, and traction sanding. Environ. Sci. Technol. 39: 699-706.

Kuula, J., Mäkelä, T., Hillamo, R. and Timonen, H. (2017). Response characterization of an inexpensive aerosol sensor. Sensors 17: 2915.

Kuuluvainen, H., Rönkkö, T., Järvinen, A., Saari, S., Karjalainen, P., Lähde, T., Pirjola, L., Niemi, J.V., Hillamo, R. and Keskinen, J. (2016). Lung deposited surface area size distributions of particulate matter in different urban areas. Atmos. Environ. 136: 105-113.

Lehtimäki, M. (1983). Modified electrical aerosol detector. In Aerosols in the mining and industrial work environments, Vol. 3, Marple, V.A. and Liu, B.Y.H. (Eds.), Ann Arbor Science Publishers, Ann Arbor, USA, p. 1135-1143.

Liu, D., Zhang, Q., Jiang, J. and Chen, D.R. (2017). Performance calibration of low-cost and portable particular matter (PM) sensors. J. Aerosol Sci. 112: 110.

Liu, H.Y., Schneider, P., Haugen, R. and Vogt, M. (2019).
Performance assessment of a low-cost $\mathrm{PM}_{2.5}$ sensor for a near four-month period in Oslo, Norway. Atmosphere 10: 41 .

Manikonda, A., Zikova, N., Hopke, P.K. and Ferro, A.R. (2016). Laboratory assessment of low-cost PM monitors. J. Aerosol Sci. 102: 29-40.

Moltchanov, S., Levy, I., Etzion, Y., Lerner, U., Broday, D.M. and Fishbain, B. (2015). On the feasibility of measuring urban air pollution by wireless distributed sensor networks. Sci. Total Environ. 502: 537-547.

Niemi, J.V., Saarikoski, S., Aurela, M., Tervahattu, H., Hillamo, R., Westphal, D.L., Aarnio, P., Koskentalo, T., Makkonen, U., Vehkamäki, H. and Kulmala, M. (2009). Long-range transport episodes of fine particles in southern Finland during 1999-2007. Atmos. Environ. 43: 1255-1264.

Niemi, J.V., Tervahattu, H., Vehkamäki, H., Kulmala, M., Koskentalo, T., Sillanpää, M. and Rantamäki, M. (2004). Characterization and source identification of a fine particle episode in Finland. Atmos. Environ. 38: 5003-5012.

Niu, J., Fau, R.P., Magee, R.F. and Nilsson, G., (2015). Spatial and temporal variability of incidental nanoparticles in indoor workplaces: Impact on the characterization of point source exposures. Environ. Sci. Processes Impacts 17: 98-109.

Ntziachristos, L., Giechaskiel, B., Ristimaki, J. and Keskinen, J. (2004). Use of a corona charger for the characterisation of automotive exhaust aerosol. $J$. Aerosol Sci. 35: 943-963.

Ntziachristos, L., Polidori, A., Phuleria, H., Geller, M.D. and Sioutas, C. (2007). Application of a diffusion charger for the measurement of particle surface concentration in different environments. Aerosol Sci. Technol. 41: 571580.

Oberdörster, G., Oberdörster, E. and Oberdörster, J. (2005). Nanotoxicology: An emerging discipline evolving from studies of ultrafine particles. Environ. Health Perspect. 113: 823-839.

Official Journal of the European Union (2008). Directive 2008/50/EC of the European parliament and the council of 21 may 2008 on ambient air quality and cleaner air for Europe. Brussels, Belgium.

Pacitto, A., Stabile, L., Moreno, T., Kumar, P., Wierzbicka, A., Morawska, L. and Buonanno, G. (2017). The influence of lifestyle on airborne particle surface area doses received by different western populations. Environ. Pollut. 232: 113-122.

Pirjola, L., Niemi, J.V., Saarikoski, S., Aurela, M., Enroth, J., Carbone, S., Saarnio, K., Kuuluvainen, H., Kousa, A., Rönkkö, T. and Hillamo, R. (2017). Physical and chemical characterization of urban winter-time aerosols by mobile measurements in Helsinki, Finland. Atmos. Environ. 158: 60-75.

Rai, A.C., Kumar, P., Pilla, F., Skouloudis, A.N., Di Sabatino, S., Ratti, C., Yasar, A. and Rickerby, D. (2017). Enduser perspective of low-cost sensors for outdoor air pollution monitoring. Sci. Total Environ. 607: 691-705.

Rajasegarar, S., Zhang, P., Zhou, Y., Karunasekera, S., 
Leckie, C. and Palaniswami, M. (2014). High resolution spatio-temporal monitoring of air pollutants using wireless sensor networks. 2014 IEEE Ninth International Conference on Intelligent Sensors, Sensor Networks and Information Processing (ISSNIP), 21-24 April 2014, Singapore, pp. 1-6.

Rivas, I., Viana, M., Moreno, T., Pandolfi, M., Amato, F., Reche, C., Bouso, L., Alvarez-Pederol, M., Alastuey, A., Sunyer, J. and Querol, X. (2014). Child exposure to indoor and outdoor air pollutants in schools in Barcelona, Spain. Environ. Int. 69: 200-212.

Rönkkö, T.J., Jalava, P.I., Happo, M.S., Kasurinen, S., Sippula, O., Leskinen, A., Koponen, H., Kuuspalo, K., Ruusunen, J., Väisänen, O., Hao, L., Ruuskanen, A., Orasche, J., Fang, D., Zhang, L., Lehtinen, K.E.J., Zhao, Y., Gu, C., Wang, Q., Jokiniemi, J., Komppula, M. and Hirvonen, M.R. (2018). Emissions and atmospheric processes influence the chemical composition and toxicological properties of urban air particulate matter in Nanjing, China. Sci. Total Environ. 639: 1290-1310.

Rostedt, A., Arffman, A., Janka, K., Yli-Ojanperä, J. and Keskinen, J. (2014). Characterization and response model of the PPS-M aerosol sensor. Aerosol Sci. Technol. 48: 1022-1030.

Saarikoski, S., Sillanpää, M., Sofiev, M., Timonen, H., Saarnio, K., Teinilä, K., Karppinen, A., Kukkonen, J. and Hillamo, R. (2007). Chemical composition of aerosols during a major biomass burning episode over northern Europe in spring 2006: Experimental and modelling assessments. Atmos. Environ. 41: 3577-3589.

Saarikoski, S., Timonen, H., Saarnio, K., Aurela, M., Järvi, L., Keronen, P., Kerminen, V.M. and Hillamo, R., (2008). Sources of organic carbon in fine particulate matter in northern European urban air. Atmos. Chem. Phys. 8: 6281-6295.

Saarnio, K., Teinilä, K., Aurela, M., Timonen, H. and Hillamo, R. (2010). High-performance anion-exchange chromatography-mass spectrometry method for determination of levoglucosan, mannosan, and galactosan in atmospheric fine particulate matter. Anal. Bioanal. Chem. 398: 2253-2264.

Sillanpää, M., Frey, A., Hillamo, R., Pennanen, A.S. and Salonen, R.O. (2005). Organic, elemental and inorganic carbon in particulate matter of six urban environments in Europe. Atmos. Chem. Phys. 5: 2869-2879.

Sillanpää, M., Hillamo, R., Saarikoski, S., Frey, A., Pennanen, A., Makkonen, U., Spolnik, Z., Van Grieken, R., Branis, M., Brunekreef, B., Chalbot, M., Kuhlbusch, T., Sunyer, J., Kerminen, V.M., Kulmala, M. and Salonen, R.O. (2006). Chemical composition and mass closure of particulate matter at six urban sites in Europe. Atmos. Environ. 40: 212-223.

Sillanpää, M., Saarikoski, S., Hillamo, R., Pennanen, A., Makkonen, U., Spolnik, Z., Van Grieken, R., Koskentalo, T. and Salonen, R.O. (2005). Chemical composition, mass size distribution and source analysis of long-range transported wildfire smokes in Helsinki. Sci. Total Environ. 350: 119-135.

Sousan, S., Koehler, K., Hallett, L. and Peters, T.M. (2017). Evaluation of consumer monitors to measure particulate matter. J. Aerosol Sci. 107: 123-133.

Sousan, S., Koehler, K., Hallett, L. and Peters, T.M., (2016). Evaluation of the Alphasense optical particle counter (OPC-N2) and the Grimm portable aerosol spectrometer (PAS-1.108). Aerosol Sci. Technol. 50: 1352-1365.

Sousan, S., Koehler, K., Thomas, G., Park, J.H., Hillman, M., Halterman, A. and Peters, T.M. (2016). Intercomparison of low-cost sensors for measuring the mass concentration of occupational aerosols. Aerosol Sci. Technol. 50: 462-473.

Timonen, H., Aurela, M., Carbone, S., Saarnio, K., Frey, A., Saarikoski, S., Teinilä, K., Kulmala, M. and Hillamo, R. (2014). Seasonal and diurnal changes in inorganic ions, carbonaceous matter and mass in ambient aerosol particles at an urban, background area. Boreal Environ. Res. 19: 71-86.

Timonen, H., Saarikoski, S., Tolonen-Kivimäki, O., Aurela, M., Saarnio, K., Petäjä, T., Aalto, P.P., Kulmala, M., Pakkanen, T. and Hillamo, R. (2008). Size distributions, sources and source areas of water-soluble organic carbon in urban background air. Atmos. Chem. Phys. 8: 5635-5647.

Todea, A.M., Beckmann, S., Kaminski, H. and Asbach, C. (2015). Accuracy of electrical aerosol sensors measuring lung deposited surface area concentrations. J. Aerosol Sci. 89: 96-109.

Todea, A.M., Beckmann, S., Kaminski, H., Bard, D., Bau, S., Clavaguera, S., Dahmann, D., Dozol, H., Dziurowitz, N., Elihn, K., Fierz, M., Liden, G., Meyer-Plath, A., Monz, C., Neumann, V., Pelzer, J., Simonow, B.K., Thali, P., Tuinman, I., van der Vleuten, A., Vroomen, H. and Asbach, C. (2017). Inter-comparison of personal monitors for nanoparticles exposure at workplaces and in the environment. Sci. Total Environ. 605-606: 926-945.

Viidanoja, J., Sillanpää, M., Laakia, J., Kerminen, V.M., Hillamo, R., Aarnio, P. and Koskentalo, T. (2002). Organic and black carbon in $\mathrm{PM}_{2.5}$ and $\mathrm{PM}_{10}$ : 1 year of data from an urban site in Helsinki, Finland. Atmos. Environ. 36: 3183-3193.

Wang, Y., Li, J., Jing, H., Zhang, Q., Jiang, J. and Biswas, P. (2015). Laboratory evaluation and calibration of three low-cost particle sensors for particulate matter measurement. Aerosol Sci. Technol. 49: 1063-1077.

Zikova, N., Hopke, P.K., and Ferro, A.R. (2017). Evaluation of new low-cost particle monitors for $\mathrm{PM}_{2.5}$ concentrations measurements. J. Aerosol Sci. 105: 2434.

Received for review, April 24, 2018 Revised, December 12, 2018 Accepted, December 20, 2018 